\title{
Modulation of the Relationship between ENSO and Its Combination Mode by the Atlantic Multidecadal Oscillation
}

\author{
Xin Geng AND WenJun Zhang \\ CIC-FEMD/ILCEC, Key Laboratory of Meteorological Disaster of Ministry of Education, Nanjing University of \\ Information Science and Technology, Nanjing, China \\ FEI-FEI JIN \\ Department of Atmospheric Sciences, School of Ocean and Earth Science and Technology, \\ University of Hawai'i at Mānoa, Honolulu, Hawaii \\ MALTE F. STUECKER \\ Department of Oceanography and International Pacific Research Center, School of Ocean and Earth Science and \\ Technology, University of Hawai'i at Mānoa, Honolulu, Hawaii
}

AARON F. Z. LEVINE

Department of Atmospheric Sciences, University of Washington, Seattle, Washington

(Manuscript received 3 October 2019, in final form 23 January 2020)

\begin{abstract}
Recent studies demonstrated the existence of a conspicuous atmospheric combination mode (C-mode) originating from nonlinear interactions between El Niño-Southern Oscillation (ENSO) and the Pacific warm pool annual cycle (AC). Here we find that the C-mode exhibits prominent decadal amplitude variations during the ENSO decaying boreal spring season. It is revealed that the Atlantic multidecadal oscillation (AMO) can largely explain this waxing and waning in amplitude. A robust positive correlation between ENSO and the C-mode is detected during a negative AMO phase but not during a positive phase. Similar results can also be found in the relationship of ENSO with 1) the western North Pacific (WNP) anticyclone and 2) spring precipitation over southern China, both of which are closely associated with the C-mode. We suggest that ENSO property changes due to an AMO modulation play a crucial role in determining these decadal shifts. During a positive AMO phase, ENSO events are distinctly weaker than those in an AMO negative phase. In addition, El Niño events concurrent with a positive AMO phase tend to exhibit a westward-shifted sea surface temperature (SST) anomaly pattern. These SST characteristics during the positive AMO phase are both not conducive to the development of the meridionally asymmetric C-mode atmospheric circulation pattern and thus reduce the ENSO/C-mode correlation on decadal time scales. These observations can be realistically reproduced by a coupled general circulation model (CGCM) experiment in which North Atlantic SSTs are nudged to reproduce a 50-yr sinusoidally varying AMO evolution. Our conclusion carries important implications for understanding seasonally modulated ENSO dynamics and multiscale climate impacts over East Asia.
\end{abstract}

\section{Introduction}

El Niño-Southern Oscillation (ENSO), the most prominent year-to-year climate fluctuation on the planet, is characterized by alternating warmer (El Niño) and colder (La Niña) sea surface temperature (SST) conditions along with a zonal atmospheric pressure

Corresponding author: Wenjun Zhang, zhangwj@nuist.edu.cn swing across the tropical Pacific basin. Although its dynamics originate in the tropical Pacific, ENSO's reach projects far beyond through atmospheric teleconnections that affect weather and climate patterns worldwide (e.g., van Loon and Madden 1981; Ropelewski and Halpert 1987; Trenberth and Caron 2000; McPhaden et al. 2006). For example, strong El Niño events are typically followed by massive summer monsoon flooding over the Yangtze River basin, home to about a third of 
the population in China (Zhang et al. 2016b). Hence, ENSO has been receiving wide attention from scientists and policymakers. In the second half of the twentieth century, great advances have been achieved in understanding the physical nature of ENSO (e.g., Bjerknes 1969; Wyrtki 1975; Rasmusson and Carpenter 1982; Zebiak and Cane 1987; Neelin et al. 1998; Wallace et al. 1998). The Bjerknes feedback loop between trade wind intensity, subsurface ocean temperature anomalies, and the zonal SST gradient in the Pacific acts as the key process amplifying initial SST and/or wind anomalies (Bjerknes 1969). However, this positive ocean-atmosphere feedback by itself does not allow for an oscillation with the observed phase transitions between ENSO warm and cold events. Subsequently, various conceptual theories were proposed to explain ENSO's phase oscillatory behavior by invoking delayed negative feedback mechanisms (e.g., Schopf and Suarez 1988; Battisti and Hirst 1989; Jin 1997a,b; Picaut et al. 1997; Weisberg and Wang 1997). For example, the ENSO recharge oscillator theory highlights the importance of the equatorial Pacific heat content discharge/recharge process along the equator (Jin 1997a,b), which is supported by the observed equatorial thermocline depth evolution (Meinen and McPhaden 2000).

The ENSO phenomenon displays a pronounced seasonal synchronization with the annual cycle (AC), with SST anomalies on average decreasing during the beginning of the year and increasing during the second half of the year (Rasmusson and Carpenter 1982; Stein et al. 2011, 2014). This tight seasonal phase-locking indicates an inherent strong interaction between ENSO and the AC. Jin et al. (1994) suggested that the nonlinear resonance between ENSO and the AC could produce new time scales and could be responsible for the genesis of ENSO's irregularity. Based on analyses of both observations and coupled general circulation model (CGCM) simulations, recent studies found that nonlinear atmospheric interactions between interannual ENSO variability and the Pacific warm pool AC gives rise to a new ENSO-dependent climate variability, which can be captured by the second empirical orthogonal function (EOF) mode of tropical Pacific surface wind anomalies (Stuecker et al. 2013, 2015a,b). This combination mode (denoted as C-mode) comprises a meridionally asymmetric atmospheric circulation pattern that includes the southward shift of central Pacific zonal wind anomalies during late winter and early spring, which is crucial for the seasonally modulated termination of ENSO events (e.g., Harrison 1987; Harrison and Vecchi 1999; Vecchi 2006; Ohba and Ueda 2009; McGregor et al. 2012; Stuecker et al. 2013). Furthermore, the C-mode causes characteristic interhemispheric sea level variability patterns in the Pacific
(Widlansky et al. 2014) and is responsible for the genesis of the anomalous low-level western North Pacific (WNP) anticyclone (Stuecker et al. 2015b). The C-mode dynamics can explain the observed meridionally antisymmetric atmospheric response over the WNP region well (Stuecker et al. 2015b), with local air-sea coupling in the WNP (Wang et al. 2000) and the delayed Indian Ocean warming capacitor effect (Yang et al. 2009; Xie et al. 2009) amplifying the C-mode response in boreal summer following an El Niño event. This anomalous WNP circulation induces precipitation anomalies over East Asia via modulating low-level moisture transports (Zhang et al. 2016a). Therefore, the C-mode plays a crucial role in both directly shaping the ENSO life cycle and in further extending ENSO's impacts toward the WNP as well as other extratropical regions.

Mathematically, the C-mode time series can be well reconstructed by a product of the Niño-3.4 index and the Pacific warm pool SST AC. The resulting C-mode time series exhibits characteristics near-annual frequencies at periods of $\sim 10$ and $\sim 15$ months (Stuecker et al. 2013, 2015b). Therefore, it is compelling to infer that the C-mode magnitude is closely connected to ENSO's characteristics, especially ENSO amplitude. Recent studies have shown that the C-mode occurs most prominently during strong El Niño events but is less pronounced during weak El Niño and La Niña events (McGregor et al. 2013; Stuecker et al. 2013). Large amplitude El Niño events generally give rise to a wellorganized WNP anticyclone and thus result in a strong connection between ENSO and the East Asian monsoon (Wang et al. 2008; Xie et al. 2010). In addition, the atmospheric circulation pattern resulting from this ENSO/AC interaction also exhibits a high dependence on the zonal structure of ENSO SST anomalies. A strong meridionally asymmetric atmospheric response (i.e., strong C-mode) appears predominantly during traditional eastern Pacific (EP) El Niño events rather than during central Pacific (CP) El Niño events (McGregor et al. 2013; Zhang et al. 2015). Importantly, both ENSO intensity and its zonal structure exhibit significant decadal variability in observations. Past ENSO activity is characterized by both periods of relative quiescence, when El Niño and La Niña events tend to be weak, and active periods when ENSO events are strong and punctuated with the occasional occurrence of extreme El Niño events (e.g., Dong et al. 2006; Lübbecke and McPhaden 2014). Significant regime changes in ENSO patterns can also be detected on decadal time scales, with El Niño events being more frequently observed in the $\mathrm{CP}$ after the late 1990s (e.g., Yeh et al. 2009; Xiang et al. 2013; Ren et al. 2013; Zhang et al. 2014; Hu and Fedorov 2018). Hence, one scientific issue remains to be answered, 
namely whether ENSO/AC interactions vary on decadal and longer time scales. If so, which external forcing is responsible for this variation?

Although previous studies have well illustrated the C-mode dynamics on seasonal-to-interannual time scales (Stuecker et al. 2013, 2015b), whether ENSO/AC interaction exhibits long-term variations has not been sufficiently elucidated. Here we focus on decadal variations of the ENSO/C-mode relationship and demonstrate that this nonstationarity can be largely attributed to ENSO property changes in response to AMO phase shifts. In the remainder of this paper, section 2 describes the utilized datasets and methodologies. The changing character of $\mathrm{ENSO} / \mathrm{AC}$ nonlinear interactions due to a decadal modulation effect by the AMO is illustrated in section 3. Next, in section 4 we explore the possible mechanisms that can explain this modulation based on both observations and a CGCM experiment. The major conclusions are summarized and discussed in section 5 .

\section{Data and methodology}

\section{a. Datasets}

The monthly datasets (1948-2018) used in this work include global SST from the National Oceanic and Atmospheric Administration (NOAA) Extended Reconstructed SST analysis, version 3 (ERSST; Smith et al. 2008). Atmospheric circulation is characterized by monthly surface $(10 \mathrm{~m})$ wind, which is obtained from the National Centers for the Environmental Prediction-National Center for the Atmospheric Research (NCEP-NCAR) reanalysis (Kalnay et al. 1996). The precipitation anomalies are investigated using both the NOAA precipitation reconstruction dataset (PREC) (Chen et al. 2002) and the station precipitation dataset provided by the China Meteorological Administration (CMA). The horizontal spatial resolution is $2^{\circ} \times 2^{\circ}$ for the SST dataset and $2.5^{\circ} \times 2.5^{\circ}$ for the precipitation and atmospheric circulation datasets.

\section{b. Methodology}

Besides simple linear statistical tools such as composite and linear regression analyses, we use a partial correlation technique (e.g., Yamagata et al. 2004; Ashok et al. 2007) to delineate the partial relationship between two variables while excluding potential influences arising from an additional independent variable. Anomalies for all fields are computed as the deviation from the long-term climatological mean (1948-2018). The linear trend was removed to avoid possible influences associated with the long-term trend. We employ several climatic indices to facilitate our analyses. The Niño-3.4 index, which is defined as the area-averaged SST anomalies in the Niño-3.4 region $\left(5^{\circ} \mathrm{S}-5^{\circ} \mathrm{N}, 120^{\circ}-170^{\circ} \mathrm{W}\right)$, is used to quantify ENSO intensity. Following conventions, we utilize a threshold of \pm 0.5 standard deviations of the Niño-3.4 index during the DJF season to define ENSO events. With this method, 22 El Niño and 26 La Niña events are identified (Table 1). The boreal winter of 1948, for example, refers to December 1948February 1949. The calendar months labeled with (0) and (1) denote the months in ENSO developing and decaying year, respectively. The AMO index is calculated as the area-averaged SST anomalies within the domain of $0^{\circ}-60^{\circ} \mathrm{N}$ and $0^{\circ}-80^{\circ} \mathrm{W}$ (Trenberth and Shea 2006). In this study, the ENSO decaying spring [MAM(1)] is our focus since the C-mode generally has its peak and exhibits the strongest decadal variations during this season (see Fig. 3). All the above indices are normalized before our analysis. All statistical significance tests were performed based on the two-tailed Student's $t$ test.

\section{c. Coupled model experiment}

Due to the relatively short observational period, a CGCM experiment is conducted with the Geophysical Fluid Dynamics Laboratory (GFDL) CM2M (Galbraith et al. 2011) model to test our observational hypotheses. The atmospheric component of the model has a $\sim 3.5^{\circ} \times 3^{\circ}$ spatial resolution with 24 vertical levels. The oceanic component has nominal $3^{\circ}$ horizontal resolution increasing to $0.6^{\circ}$ latitudinal resolution at the equator and 28 vertical levels including five in the upper $50 \mathrm{~m}$. In the experiment, the North Atlantic SSTs are relaxed to the monthly climatology plus a 50-yr sinusoidally varying AMO anomaly with a 2-day relaxation time (Levine et al. 2017). The AMO anomaly is calculated by regressing the SST anomalies upon the AMO index. Outside of the prescribed region the SSTs can evolve freely. The AMO-forced experiments are integrated for 500 years, yielding nine complete AMO cycles because of a phase shift. We compute the anomalies by subtracting the long-term monthly mean from the simulation itself.

\section{Decadal variations of ENSO combination mode amplitude}

To obtain the spatial wind structures and temporal variability associated with the $\mathrm{C}$-mode, we first perform a multivariate EOF analysis on the surface zonal and meridional wind anomalies over the equatorial Pacific $\left(10^{\circ} \mathrm{S}-10^{\circ} \mathrm{N}, 100^{\circ} \mathrm{E}-90^{\circ} \mathrm{W}\right)$ and then obtain the spatial patterns by regressing the wind anomalies onto the leading two normalized principal components (PCs). Figure 1 shows the leading two EOF spatial patterns and their associated PCs, which respectively account 
TABLE 1. El Niño and La Niña events for the 1948-2017 period.

\begin{tabular}{cc}
\hline \hline El Niño events & La Niña events \\
\hline $1951,1953,1957,1958,1963,1965,1968$, & $1949,1950,1954,1955,1964,1967,1970$, \\
$1969,1972,1976,1977,1982,1986,1987$, & $1971,1973,1974,1975,1984,1988,1995$, \\
$1991,1994,1997,2002,2004,2006$, & $1998,1999,2000,2005,2007,2008,2010$, \\
2009,2015 & $2011,2012,2013,2016,2017$ \\
\hline
\end{tabular}

for $29.1 \%$ and $14.2 \%$ of the total variance and are well separated from each other (North et al. 1982). The first EOF pattern (EOF1) displays equatorially quasi-symmetric westerly wind anomalies over the western-central Pacific (Fig. 1a). The corresponding time series (i.e., PC1) is highly correlated with the commonly used Niño-3.4 index $(R=0.82)$, which suggests that this mode represents the direct linear atmospheric response to ENSO SST anomalies. Because of the high consistency of the Niño-3.4 index and PC1, we will use the Niño-3.4 index instead of PC1 in the remainder of the paper to capture ENSO variability. In contrast, the EOF2 wind anomaly pattern exhibits meridionally antisymmetric wind anomalies, which feature a strong anomalous WNP anticyclone and pronounced meridional shear of anomalous zonal wind across the equator (Fig. 1b), in accordance well with the results displayed in previous studies (Stuecker et al. 2013; Zhang et al. 2016a). The southward shift of central Pacific low-level wind anomalies and the WNP anticyclone are two primary characteristics of the EOF2 mode (Fig. 1b) and important for the fast decay of strong El Niño events (McGregor et al. 2012), thus playing an important role in seasonally modulated ENSO dynamics. In addition, this EOF2 helps ENSO expand its impacts toward off-equatorial regions, where the WNP anticyclone serves as the key system bridging ENSO and East Asian monsoon climate (Zhang et al. 1996; Wang et al. 2000; Yang et al. 2007; Xie et al. 2009). This dominant wind anomaly pattern has been referred to as a combination mode (C-mode), which originates from the atmospheric nonlinear interactions between ENSO
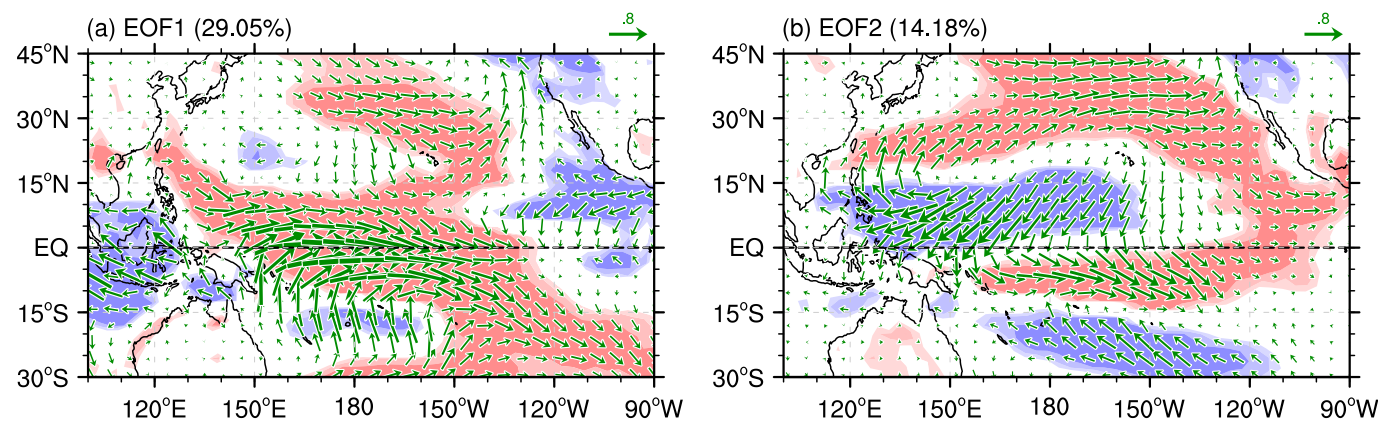

(c) PC1 and PC2

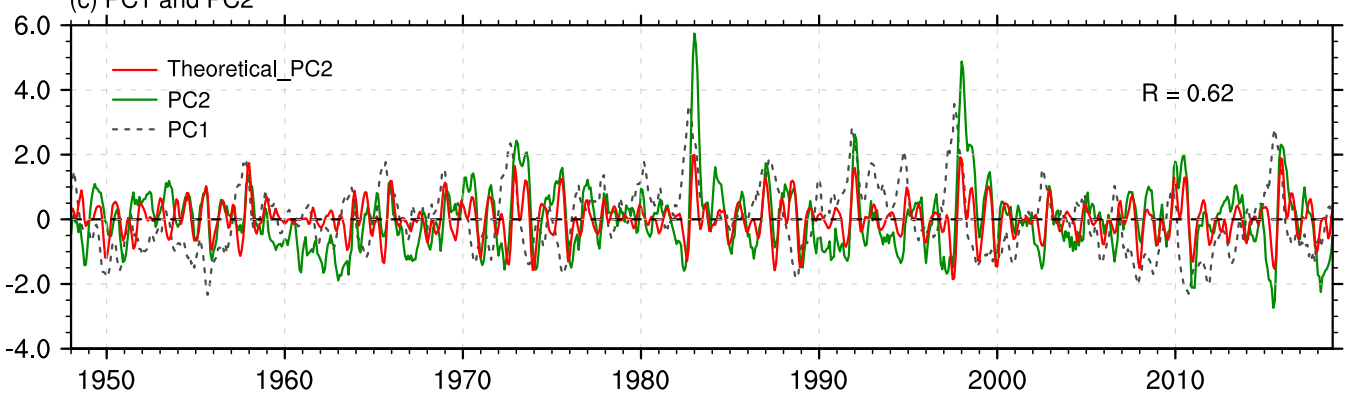

FIG. 1. (a),(b) The two leading EOF spatial patterns and (c) their corresponding normalized time series (PC) of surface wind anomalies $\left(\mathrm{m} \mathrm{s}^{-1}\right)$ over the tropical Pacific for the 1948-2017 period. The EOF spatial patterns are obtained by regression of the normalized PCs on the surface wind anomalies. The theoretical PC2 is computed as the product of the Niño-3.4 index and the annual cycle $(\mathrm{N} 3.4 \times$ annual cycle $)$ and is shown together with the correlation coefficients $(R)$ between the original and theoretical PC2 in (c). Different red and blue shadings in (a) and (b) indicate westerly and easterly anomalies that exceed the $90 \%, 95 \%$, and $99 \%$ confidence levels, respectively. 
and the western tropical Pacific warm pool AC (Stuecker et al. 2013, 2015a). Theoretically, the PC2 can be approximately represented as

$$
\text { C-mode }(t)=\operatorname{Niño} 3.4(t) \cos \left(\omega_{a} t-\varphi\right) .
$$

Here, $\omega_{a}$ denotes the angular frequency of the AC and $\varphi$ represents a 1-month phase shift. This theoretical PC2 captures the observed PC2 time series realistically with a high intercorrelation coefficient reaching 0.62 , consistent with previous studies (Stuecker et al. 2013; Zhang et al. 2016a).

The C-mode is intrinsically associated with ENSO variability and the Pacific warm pool AC (Stuecker et al. 2013). During an El Niño event, while the Niño-3.4 typically reaches its peak in the boreal winter season, the $\mathrm{PC} 2$ remains negative until October of the El Niño developing year and then reverses its sign abruptly, generally lagging the Niño-3.4 index by about 2 months and reaching its peak value during the following late winter and early spring season. An approximately opposite picture is observed during La Niña events (Fig. 2). It can be inferred that the $\mathrm{PC} 2$ is highly related to Niño3.4 (i.e., PC2 being the amplitude modulated ENSO signal by the AC), which is especially evident during the winter and spring seasons. To inspect possible decadal variations of the $\mathrm{C}$-mode response, in Fig. 3 we display the 15-yr running correlation between the DJF Niño-3.4 index and PC2 in different months. During the ENSO mature winter, little decadal variability can be detected in the relationship between Niño-3.4 and the C-mode. However, prominent decadal nonstationary behavior of the relationship is detected during the ENSO decaying spring season. The Niño-3.4 index is positively correlated with the MAM PC2 from the mid-1960s to mid-1990s, with an El Niño event being accompanied by a positive C-mode index. In contrast, no statistically significant relationship between them can be observed during other periods. Here, a sliding 15 -yr window is used to detect the Niño-3.4/C-mode relationship on decadal time scales. The qualitative conclusions remain unchanged if we utilize other moving windows, such as 13 and 17 years (not shown). Considering that boreal spring is the season when the C-mode response is generally strong and also exhibits considerable decadal variations, we focus the investigation on this season hereafter.

To further illustrate the decadal variability of the ENSO/C-mode linkage, we in Fig. 4 show the 15 -yr running correlation between the DJF Niño-3.4 and MAM PC2 (red solid line) from 1948 to 2018. It is clear that the Niño-3.4/PC2 relationship exhibits significant decadal variations with statistically significant correlations

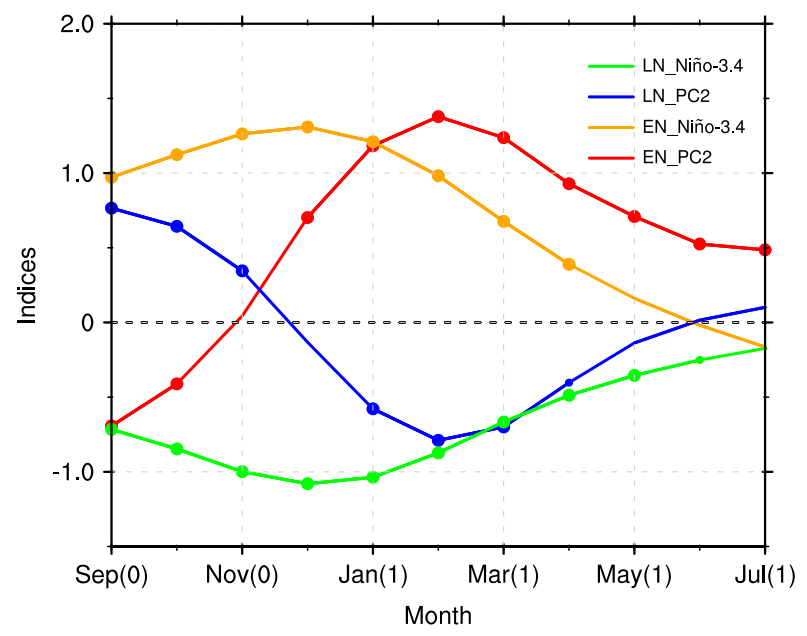

FIG. 2. Composite monthly evolutions of the normalized Niño3.4 and PC2 indices for El Niño and La Niña events during the 1948-2017 period. Small and big dots indicate values exceeding the $95 \%$ and $99 \%$ confidence levels, respectively.

at the $99 \%$ confidence level occurring primarily during the period from the mid-1960s to mid-1990s. As a key component of the C-mode, the relationship of the WNP anticyclonic low-level circulation anomalies with ENSO is also examined. Here, a WNP anticyclone index (WNPACI) is defined as the 850 -hPa streamfunction averaged over the region $5^{\circ}-25^{\circ} \mathrm{N}$ and $90^{\circ}-150^{\circ} \mathrm{E}$. It can be seen that the 15 -yr running correlation between the MAM WNPACI and the previous DJF Niño-3.4 index (black solid line in Fig. 4) displays a similar feature with that of the C-mode on decadal time scales.

It is well known that during an El Niño mature winter and decaying spring the anomalous WNP anticyclone enhances moisture transport to East Asia and thereby leads to more precipitation over southern China (e.g., Wang et al. 2000; Zhang et al. 2017). This is confirmed by Figs. $5 \mathrm{a}$ and $5 \mathrm{~b}$, which show regression maps of the spring precipitation anomalies over China onto the preceding DJF Niño-3.4 and simultaneous PC2 indices, respectively. Considering that DJF Niño-3.4 and MAM PC2 are highly correlated, partial regression patterns of the precipitation anomalies are displayed in Figs. $5 \mathrm{c}$ and $5 \mathrm{~d}$ to explore the independent influences from Niño-3.4 and $\mathrm{PC} 2$, respectively. We can see a clear statistically significant positive precipitation response to the $\mathrm{C}$-mode over southeastern China (Fig. 5d), but no statistically significant signal coming from the Niño-3.4 index (Fig. 5c). These results suggest that the ENSO SST forcing itself is not able to produce significant precipitation anomalies over southern China. Instead, ENSO's impact is conveyed to East Asia mainly through the C-mode capturing $\mathrm{ENSO} / \mathrm{AC}$ interaction, which is consistent with previous studies (Zhang et al. 2016a). Since the C-mode 


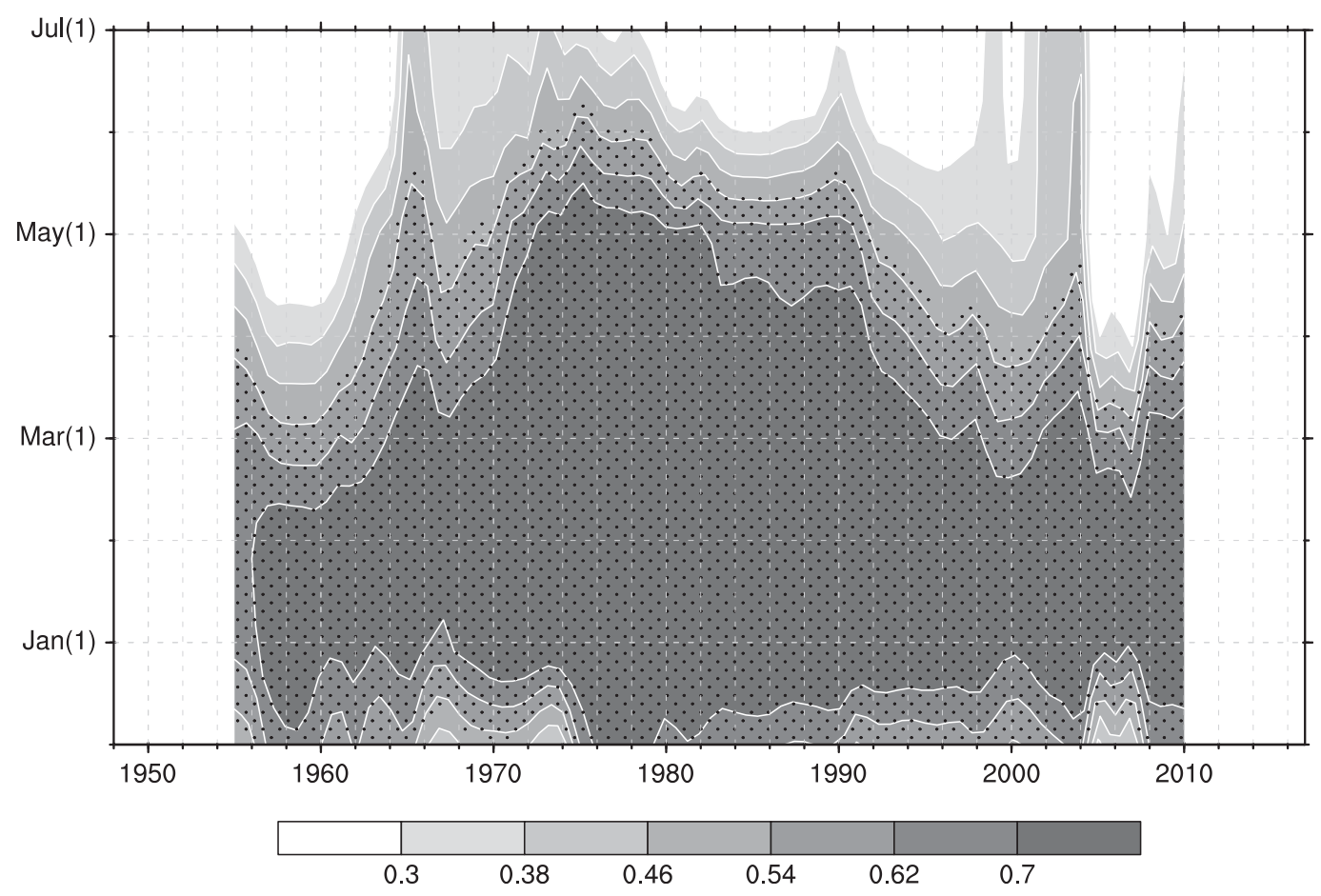

FIG. 3. 15-yr running correlation coefficients between the DJF Niño-3.4 index and the PC2 time series as a function of year ( $x$ axis) and the PC2 calendar month after the ENSO peak ( $y$ axis) during the 1948-2017 period. Year in the $x$ axis denotes the middle year of each 15-yr window. Correlation coefficients exceeding the $95 \%$ significance level are marked with black dots.

response to ENSO shows variable strength on decadal time scales, we expect that the related spring precipitation anomalies over southern China should also display similar variations. Because the leading EOF captures monopole precipitation anomalies over southern China (You and Jia 2018), we here utilize the leading PC of the
East Asian $\left(15^{\circ}-55^{\circ} \mathrm{N}, 100^{\circ}-135^{\circ} \mathrm{E}\right)$ spring precipitation anomalies (PREC_PC1) to measure the intensity of precipitation anomalies over southern China. A positive PREC_PC1 index indicates precipitation surpluses in this region. Next, we compute the 15 -yr running correlation coefficients between the DJF Niño-3.4 and

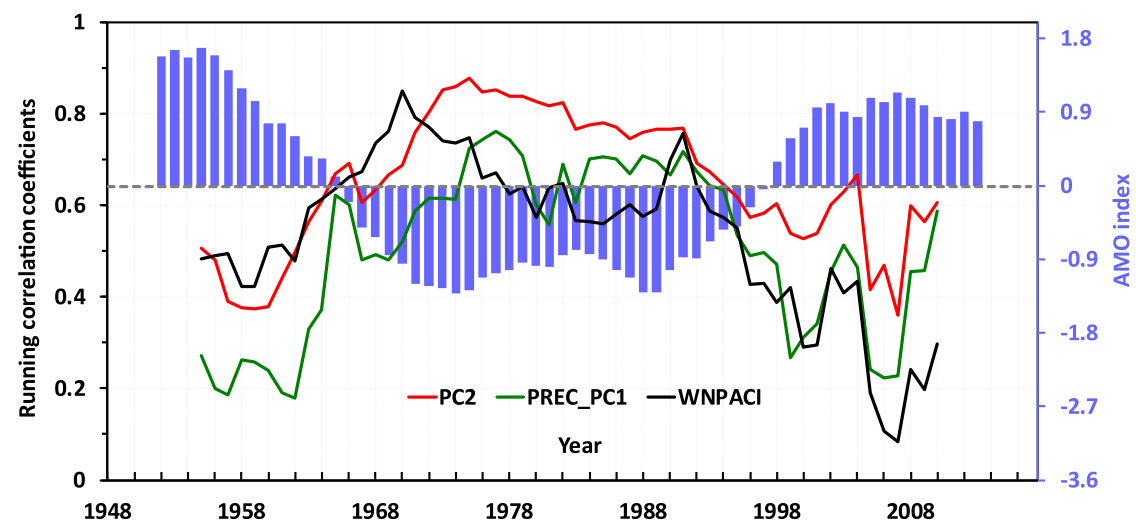

FIG. 4. The AMO index (9-yr running average; blue bars) and the 15 -yr running correlation for the DJF Niño-3.4 index with the subsequent MAM PC2 (red solid curve), the PREC_PC1 [the leading PC of precipitation anomalies in East China $\left(15^{\circ}-55^{\circ} \mathrm{N}, 100^{\circ}-135^{\circ} \mathrm{E}\right)$; green solid curve], and the anomalous WNP anticyclone index (WNPACI; black solid curve) during the 1948-2017 period. The corresponding dashed lines indicate the $99 \%$ significance levels for the correlation coefficients. 
(a) Regression on DJF Niño 3.4

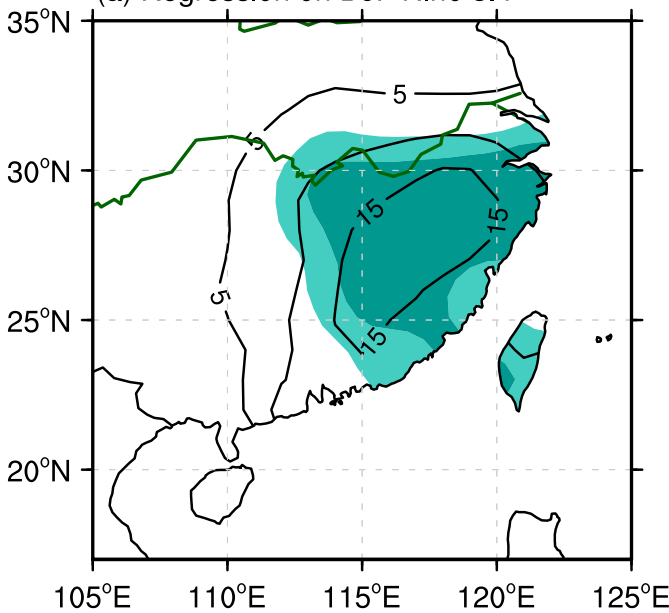

(c) Partial Regression on DJF Niño 3.4

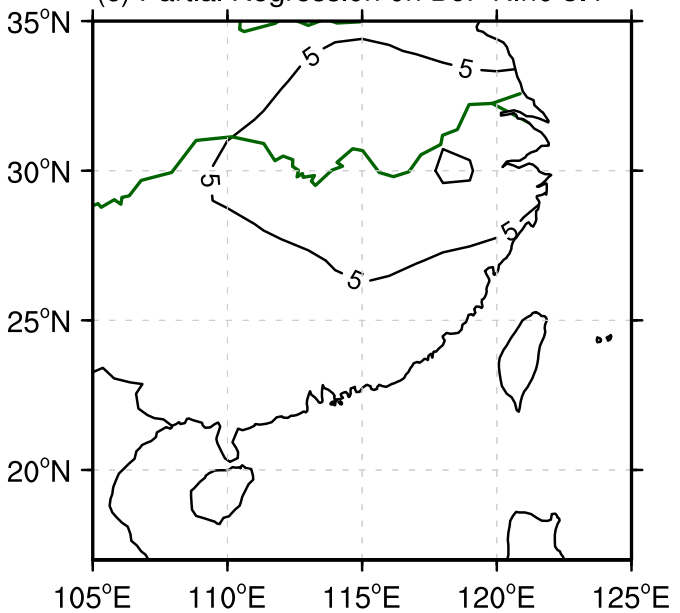

(b) Regression on MAM PC2

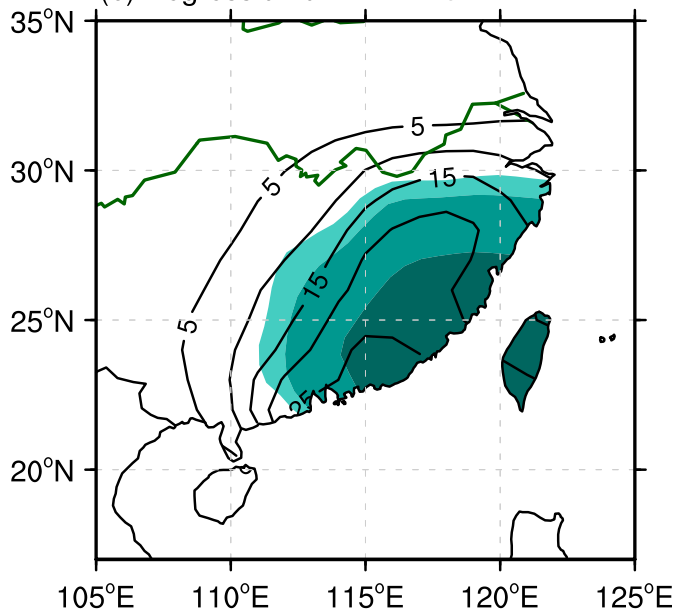

(d) Partial Regression on MAM PC2

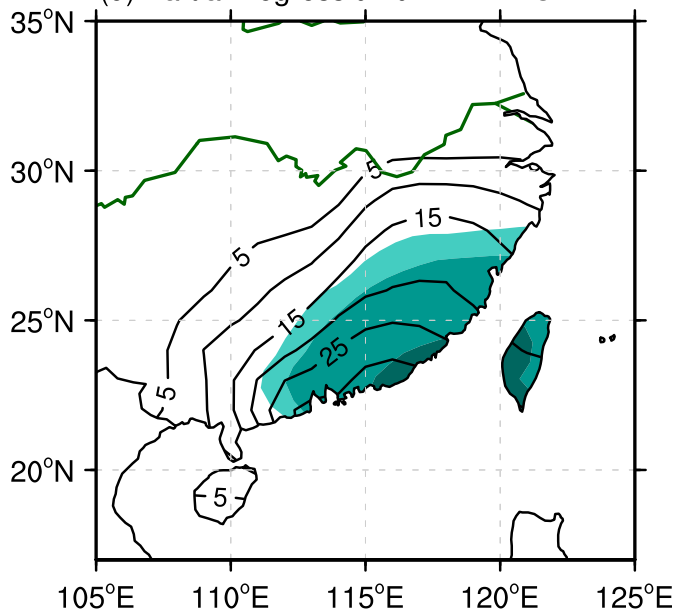

FIG. 5. Regressions of MAM precipitation anomalies (contours in $\mathrm{mm} \mathrm{day}^{-1}$, from 5 to 20 by 5 ) in southern China onto the (a) preceding DJF Niño-3.4 index and (b) simultaneous PC2 index for the 1948-2017 period. (c),(d) As in (a),(b), but for partial regressions removing linearly the impact of simultaneous PC2 index and preceding DJF Niño-3.4 index, respectively. Shadings indicate regression coefficients exceeding the $90 \%, 95 \%$, and $99 \%$ confidence levels, respectively.

PREC_PC1 (green solid line in Fig. 4). Similar to the PC2 and WNPACI, the relationship between the PREC_PC1 and ENSO also exhibits prominent decadal variations with statistically significant correlations only occurring during the period from the mid-1960s to the mid-1990s. These results demonstrate that both the ENSO/C-mode relationship and ENSO-associated climate impacts over East Asia vary on decadal time scales.

To explore which external forcing might be responsible for these decadal variations, we show in Fig. 4 also the 9-yr running averaged AMO index (blue bars), given that the $\mathrm{AMO}$ has been widely proposed as an important external forcing responsible for ENSO property changes and variations of ENSO-related anomalous atmospheric responses on decadal time scales (Dong et al. 2006; Yu et al. 2015; Levine et al. 2017; Geng et al. 2017, 2018). It can be seen that the AMO index exhibits a positive phase before the mid-1960s and after the mid-1990s, while showing a negative phase during the interim period, thus exhibiting an approximate inverse temporal evolution with the running correlations shown in the same figure. Prominent $\mathrm{C}$-mode responses during the decaying spring can be detected primarily during the negative AMO phase but not during the positive phase. This correspondence motivates our hypothesis that the $\mathrm{C}$-mode response to ENSO could be modulated by the AMO.

We then categorize the whole time period into two epochs according to the AMO phase and then display the relationship of ENSO with the C-mode during its 

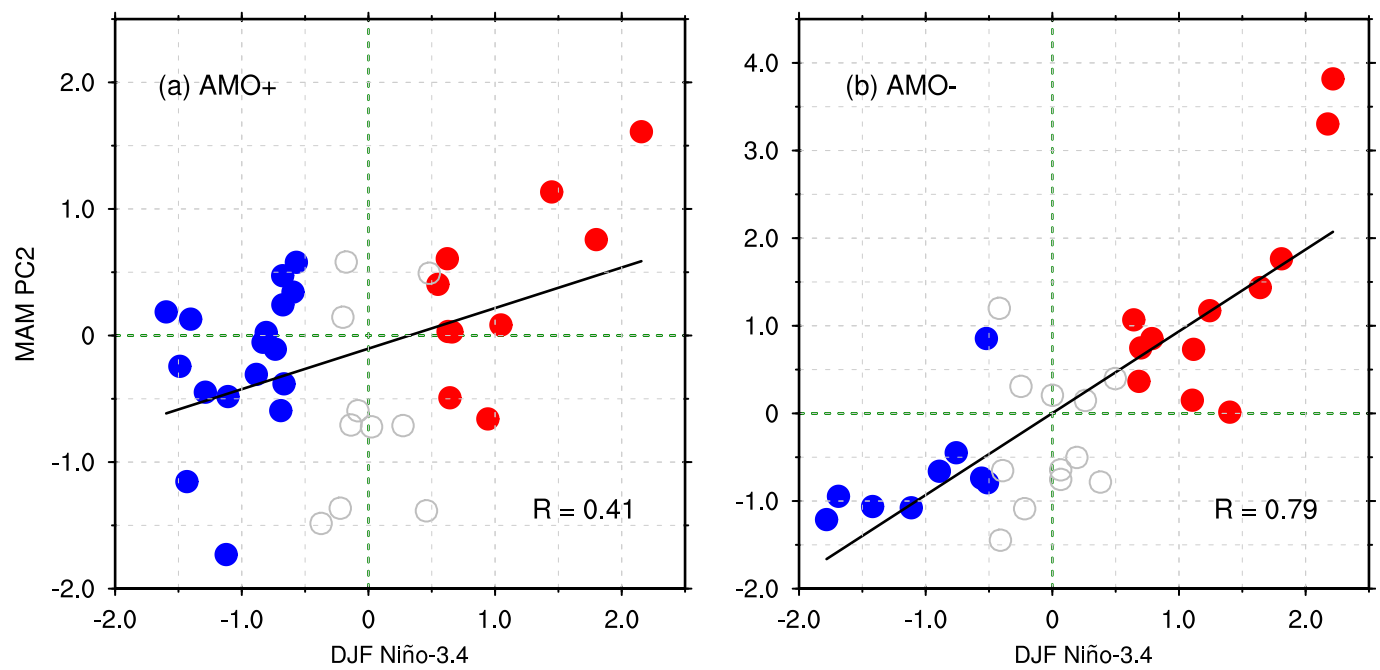

FIG. 6. Scatterplot of the MAM PC2 and preceding DJF Niño-3.4 indices during (a) positive and (b) negative AMO phases with the corresponding linear regression lines (black lines). Neutral conditions, El Niño events, and La Niña events, are indicated by hollow gray, red solid, and blue solid circles, respectively. The corresponding correlation coefficients for the two periods $(R)$ are also displayed.

decaying spring season for each epoch (Fig. 6). When the AMO is in its negative phase, nearly all ENSO events ( 20 out of 21 ; over $95 \%$ ) are accompanied by a same-sign $\mathrm{C}$-mode response in the decaying spring season, and the correlation coefficient for the period reaches 0.79 (exceeding the $99 \%$ confidence level). In contrast, only 18 out of 27 ENSO events are accompanied by a same-sign C-mode response during the positive AMO phase. The correlation coefficient is reduced to 0.41 , which is not significant at the $99 \%$ confidence level. The average C-mode amplitude is also smaller than that during the negative AMO phase, suggesting that the $\mathrm{ENSO} / \mathrm{AC}$ interaction is weakened and/or that it projects onto a different (e.g., more meridionally symmetric) pattern during the positive AMO phase. To further illustrate the AMO modulation effect on the ENSO/C-mode relationship, we categorize ENSO events into four types according to the AMO phase, that is, El Niño events during a positive AMO phase $(\mathrm{AMO}+/ \mathrm{El}$ Niño) and during a negative AMO phase (AMO-/El Niño), as well as La Niña events during a positive AMO phase (AMO+/La Niña) and during a negative AMO phase (AMO-/La Niña) (see Table 2).
The composite surface wind and precipitation anomalies over the tropical Pacific for the four cases are displayed in Fig. 7. The El Niño events concurrent with a positive AMO phase show a statistically significant atmospheric response only in few areas of the tropical Pacific. Neither the characteristic anomalous WNP anticyclone nor a meridional shear of anomalous zonal wind across the equator can be clearly identified. The surface wind anomalies for an AMO+/La Niña decaying spring somewhat produce a pattern with meridional shear of anomalous zonal wind and statistically significant precipitation anomalies in the equatorial Pacific, however, the characteristic WNP circulation pattern is also absent. In contrast, both El Niño and La Niña events in the AMO negative phase are associated with pronounced precipitation anomalies and a statistically significant C-mode-like wind patterns in the tropical Pacific (including both the WNP circulation pattern and the characteristic meridional shear of anomalous zonal wind in the central Pacific), further confirming the AMO modulation effect on the ENSO/C-mode relationship. We emphasize that (as for La Niña events) the meridional shear of anomalous zonal wind is stronger in an AMO positive phase, whereas the WNP circulation

TABLE 2. Category of ENSO events for the 1948-2017 period according to the AMO phase.

\begin{tabular}{cccc}
\hline \hline AMO+/El Niño & AMO-/El Niño & AMO+/La Niña & AMO-/La Niña \\
\hline 1951, 1953, 1957, 1958, 1963, & 1965, 1968, 1969, 1972, 1976, & $1949,1950,1954,1955,1964$, & $1967,1970,1971,1973,1974$, \\
2002, 2004, 2006, 2009, 2015 & $1977,1982,1986,1987,1991$, & $1998,1999,2000,2005,2007$, & $1975,1984,1988,1995$
\end{tabular}


(a) UV10 \& Prec in AMO+/EI Niño

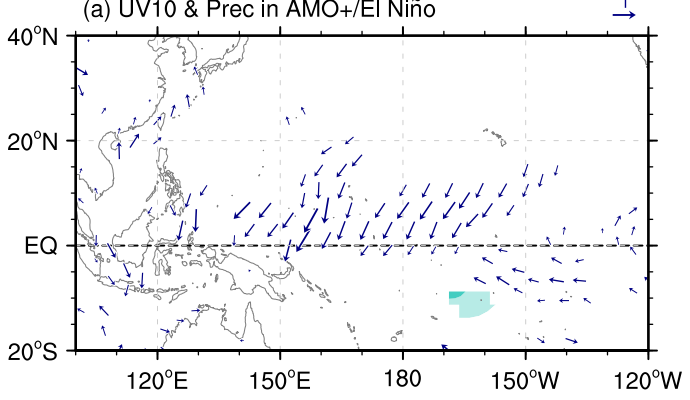

(b) UV10 \& Prec in AMO-/EI Niño

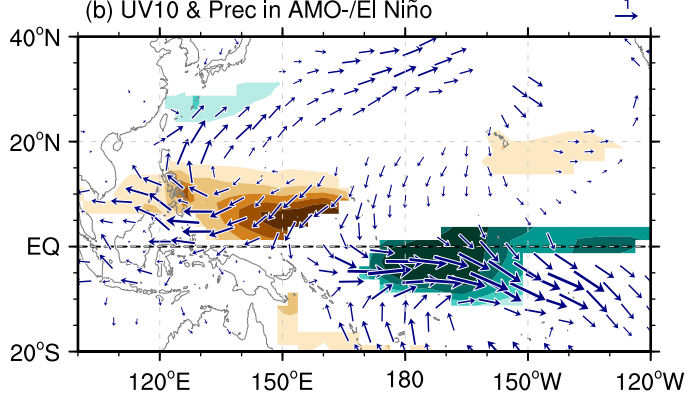

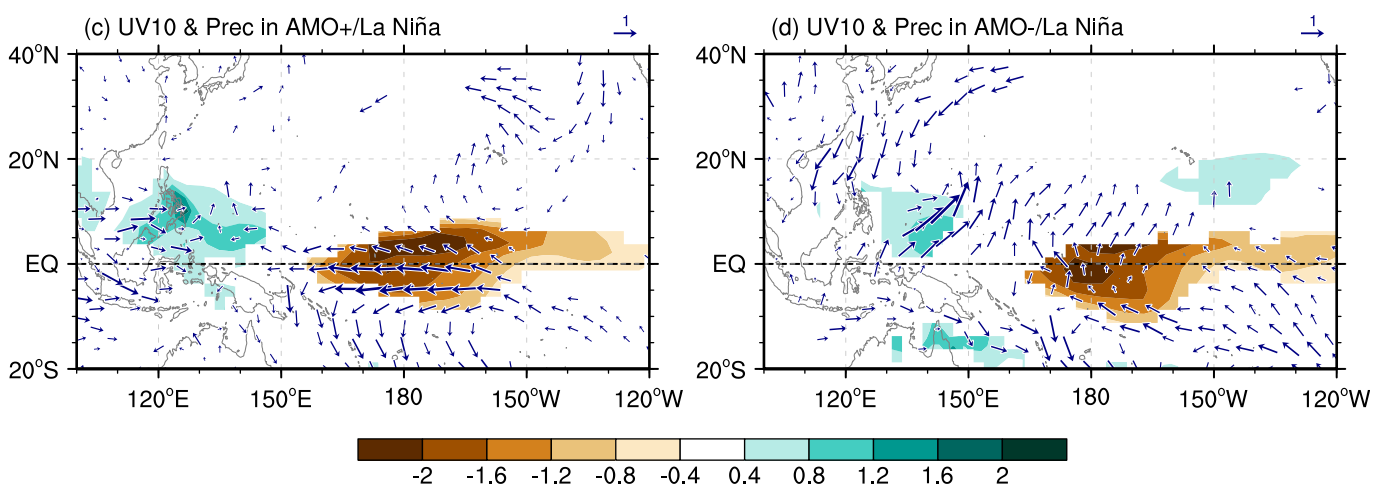

FIG. 7. Composite MAM surface wind (vectors in $\mathrm{m} \mathrm{s}^{-1}$ ) and precipitation (shadings in $\mathrm{mm} \mathrm{day}^{-1}$ ) anomalies in the tropical Pacific during (a) AMO+/El Niño, (b) AMO-/El Niño, (c) AMO+/La Niña, and (d) AMO-/La Niña events for the 1948-2017 period. The wind and precipitation anomalies are only displayed when they are statistically significant at the $95 \%$ confidence level.

pattern is more pronounced in an AMO negative phase (Figs. 7c,d). This inconsistency is possibly associated with the atmospheric background change in the tropical Pacific due to AMO forcing. Atlantic warming could lead to an intensification of Walker circulation, with strengthened precipitation and easterly surface wind anomalies in the central-eastern tropical Pacific (not shown) (Kucharski et al. 2011; McGregor et al. 2014; Zanchettin et al. 2016). As a result, the tropical atmospheric anomalies are strengthened for $\mathrm{AMO}+/ \mathrm{La}$ Niña but weakened for $\mathrm{AMO}-/ \mathrm{La}$ Niña decaying spring seasons.

\section{Possible modulation mechanisms by the AMO}

We now turn to investigate the possible mechanisms responsible for the AMO modulation of the C-mode response. Figure 8 shows the composite time evolution of the zonal mean SST anomaly in the tropical $\left(6^{\circ} \mathrm{S}-6^{\circ} \mathrm{N}\right)$ Pacific during the ENSO life cycle for the above four cases. ENSO SST anomalies typically mature in December, but their composite magnitudes and spatial structures are different for the different AMO phases. The El Niño events occurring in a positive AMO phase tend to peak at $\sim 1.0^{\circ} \mathrm{C}$ with the maximum SST anomaly located at $\sim 140^{\circ} \mathrm{W}$ (Fig. $8 \mathrm{a}$ ). In contrast, the maximum intensity for the $\mathrm{AMO}-/ \mathrm{El}$ Niño SST anomaly reaches $\sim 1.4^{\circ} \mathrm{C}$ and is located at $\sim 120^{\circ} \mathrm{W}$, a larger amplitude and farther eastward shifted pattern compared with the AMO+/El Niño case (Fig. 8b). In regard to the La Niña events, although the zonal locations of the maximum SST anomaly center do not show an apparent change between the two cases (both located at $\sim 140^{\circ} \mathrm{W}$ ), we observe a pronounced magnitude difference for the SST anomalies. The average SST anomaly magnitude of the AMO-/La Niña events is larger than that of the AMO+/La Niña case. These results are consistent with various previous studies (e.g., Dong et al. 2006; Timmermann et al. 2007; Kang et al. 2014; Levine et al. 2017; Hu and Fedorov 2018; Park and Li 2019), which argue that a positive AMO phase tends to produce weaker ENSO variability. A positive AMO is conducive to an intensified Walker circulation and enhanced trade winds in the western and central tropical Pacific. This basic state change is associated with a deepened thermocline and reduced vertical stratification in the equatorial Pacific, which weakens the coupled instability through which ENSO events grow (Zebiak and Cane 1987; Jin et al. 2006), hence reducing ENSO amplitude (Dong et al. 2006; Dong and Sutton 2007; Timmermann et al. 2007; Li et al. 2016). According to Eq. (1), a weaker ENSO magnitude yields a weaker ENSO/AC 
(a) SST anomaly during AMO+/EI Niño

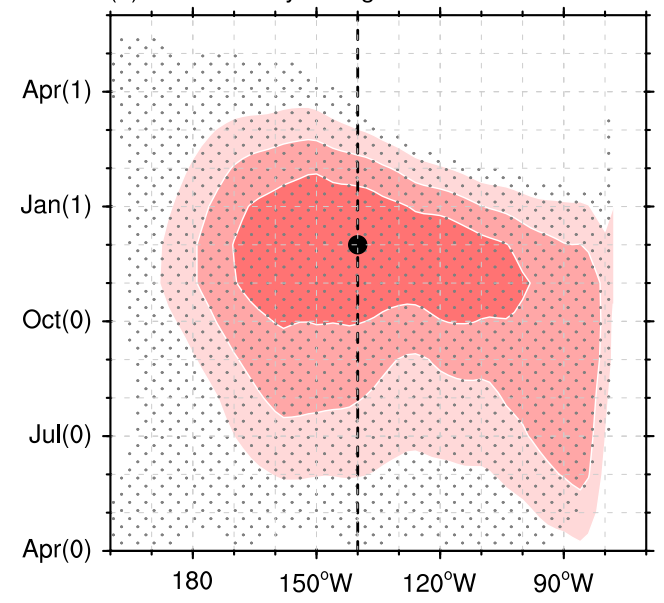

(c) SST anomaly during AMO+/La Niña

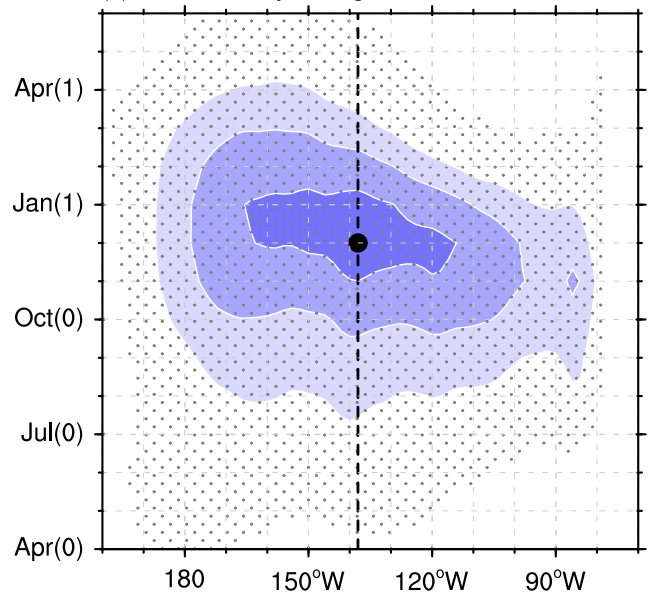

(b) SST anomaly during AMO-/EI Niño

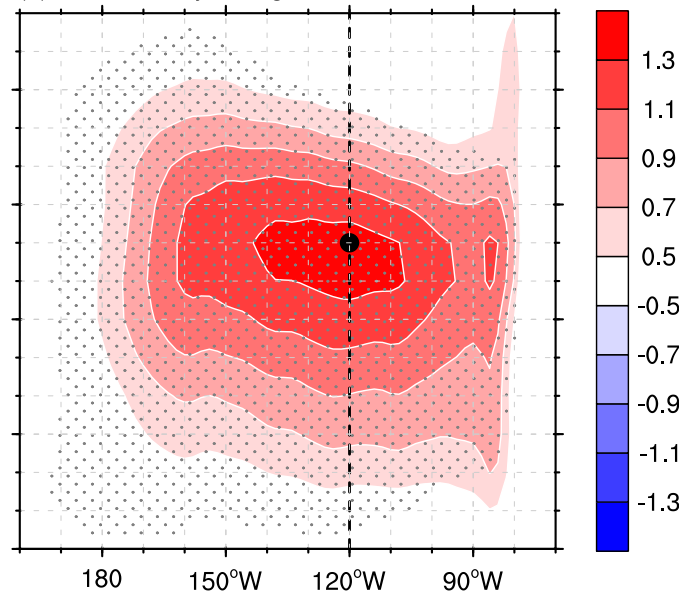

(d) SST anomaly during AMO-/La Niña

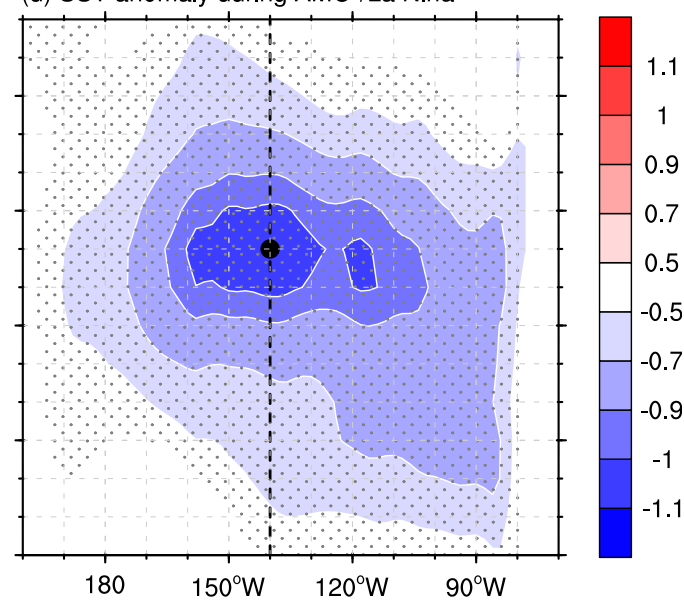

FIG. 8. Composite SST anomaly temporal evolution (shadings in $\left.{ }^{\circ} \mathrm{C}\right)$ in the tropical $\left(6^{\circ} \mathrm{S}-6^{\circ} \mathrm{N}\right)$ Pacific for (a) AMO+/El Niño, (b) AMO-/El Niño, (c) AMO+/La Niña, and (d) AMO-/La Niña events during the 1948-2017 period. Black dots and dashed vertical lines respectively denote the locations and longitudes of either maximum or minimum SST anomalies during the ENSO life cycle. Values exceeding the $95 \%$ confidence level are marked by small gray dots.

interaction, and thus the $\mathrm{C}$-mode response is modulated by the AMO via its impact on ENSO amplitude.

In addition to ENSO magnitude, we can also observe prominent differences in the zonal structure of the ENSO SST anomaly in Fig. 8. While the La Niña SST longitudinal position is basically invariant with the AMO phase, El Niño events bear distinct zonal structures of the SST anomaly during different AMO phases. The SST anomalies for the AMO+/El Niño case are westward shifted compared with those of the AMO-/El Niño case. The maximum SST anomalies along the equator are respectively located at $\sim 140^{\circ} \mathrm{W}$ and $\sim 120^{\circ} \mathrm{W}$ for the $\mathrm{AMO}+/ \mathrm{El}$ Niño and AMO-/El Niño composites. This result is consistent with previous studies ( $\mathrm{Yu}$ et al. 2015; Hu and Fedorov 2018; Park and Li 2019), which suggested a physical linkage between North Atlantic warming and the zonal structure of El Niño SST anomalies. In their arguments, a positive AMO leads to an intensification of the Pacific subtropical high and/or stronger-than-average background trade winds in both zonal and meridional components, which in turn favors the development of more CP El Niño events in the tropical Pacific. It is demonstrated that the longitudinal position of El Niño SST anomalies has notable impacts on the C-mode response. In contrast to EP El Niño events, the westward shifted SST anomalies during CP El Niño tend to excite more equatorially symmetric convection anomalies on both sides of the equator due to the high climatological SSTs in the warm pool region and the nonlinear SST-convection relationship, which in turn leads to a weaker meridionally asymmetric C-mode response (McGregor et al. 2013; Zhang et al. 2015). 


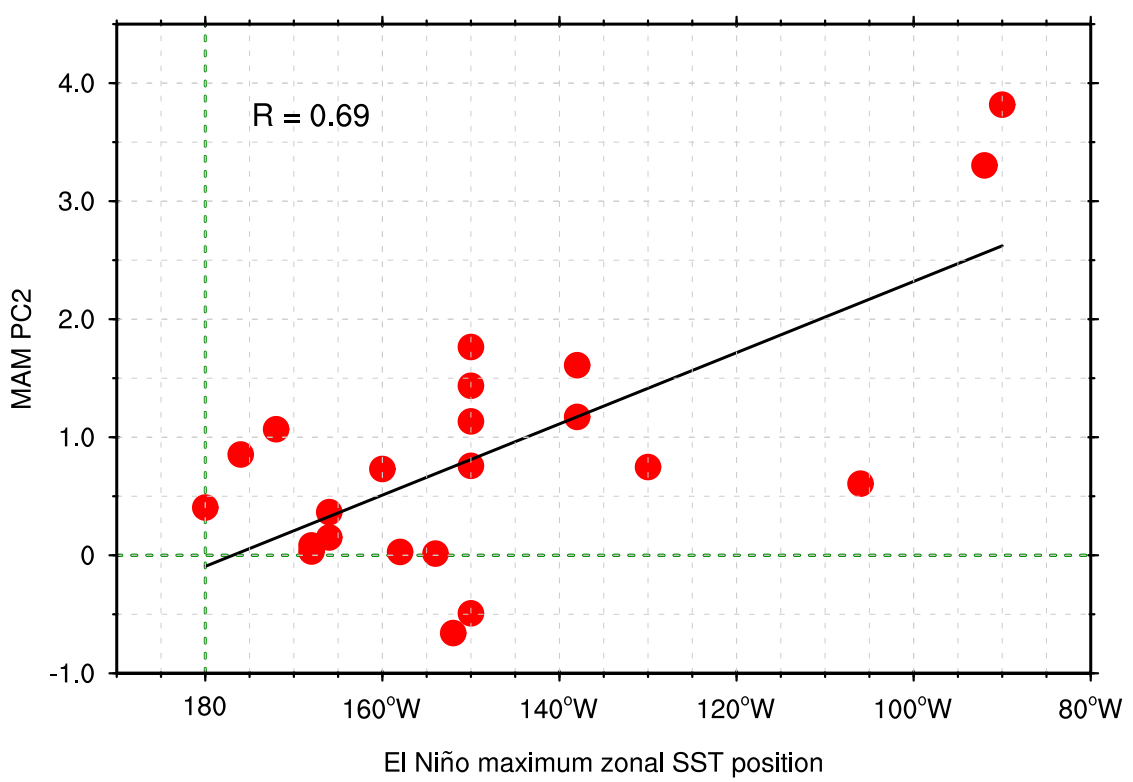

FIG. 9. Scatterplot of the MAM PC2 index and longitudinal position of the maximum SST anomalies in the tropical $\left(5^{\circ} \mathrm{S}-5^{\circ} \mathrm{N}\right)$ Pacific during the winter and spring season (DJFMAM) for all El Niño events. The black line denotes the corresponding linear regression line and the correlation coefficient $(R)$ is shown as an inset.

Inspired by these studies, we examine in Fig. 9 the possible effect of the zonal El Niño SST anomaly location on the C-mode response amplitude. A close linear interrelationship $(R=0.69$, exceeding the $99 \%$ confidence level $)$ is clearly detected, suggesting that the $\mathrm{C}$-mode response during an El Niño decaying spring tends to be weaker as the El Niño SST anomaly is shifted more westward, which provides further support for our hypothesis. To summarize, these observational results indicate that the decadal variation of the ENSO/C-mode relationship is largely determined by the changes of both ENSO amplitude and El Niño SST zonal structure due to an AMO modulation.

Due to the inherent limitation of diagnosing AMOrelated impacts from the relatively short observational record, we conducted an experiment with the GFDL $\mathrm{CM} 2 \mathrm{M}$ to further test our hypothesis that the AMO modulates the ENSO/C-mode relationship on decadal time scales. Here, the GFDL CM2M is utilized since the model simulates a relatively realistic $\mathrm{C}$-mode response both in its spatial wind structures and temporal variability (Ren et al. 2016; Stuecker et al. 2015b). The model has also been widely used to investigate multitemporal and multiple spatial scale interactions, as well as the impacts of the ENSO/AC nonlinear interactions (Levine et al. 2017, 2018). We emphasize however that the model inevitably suffers from biases similar to those of other climate models. For example, the temporal correlation of the simulated MAM PC2 with the preceding DJF Niño-3.4 index is 0.19 , much weaker than the 0.65 value seen in observations. This bias may be subject to the westward shifted wind anomalies manifested in the $\mathrm{C}$-mode spatial pattern (not shown) (Ren et al. 2016), which is associated with a weaker amplitude and more westward shift of ENSO SST anomalies in the current generation of climate models (e.g., Guilyardi et al. 2009; Bellenger et al. 2014; Van Oldenborgh et al. 2005).

As done in Fig. 4, we calculate the 15-yr running correlation between DJF Niño-3.4 and the following MAM PC2 based on the AMO-forced model simulation. The simulation has nine complete AMO cycles and thus nine ensembles for the running correlation can be obtained. The red solid line in Fig. 10 displays the composite running correlation. We can see that the simulated $\mathrm{ENSO} / \mathrm{C}$-mode relationship varies on decadal time scales. Although the AMO index and running correlation in the simulation do not agree as well with each other as seen in the observations, their linkage is qualitatively reproduced. During a negative AMO phase, ENSO tends to be accompanied by a same-sign C-mode response in its decaying spring season. In contrast, ENSO winters are generally followed by only weak C-mode-like atmospheric patterns in the subsequent spring during a positive AMO phase. Next, we calculate the East Asian PREC_PC1 during the spring season and its relationship with the DJF Niño-3.4 index in the AMO pacemaker simulations (Fig. 10). Resembling the ENSO/C-mode 


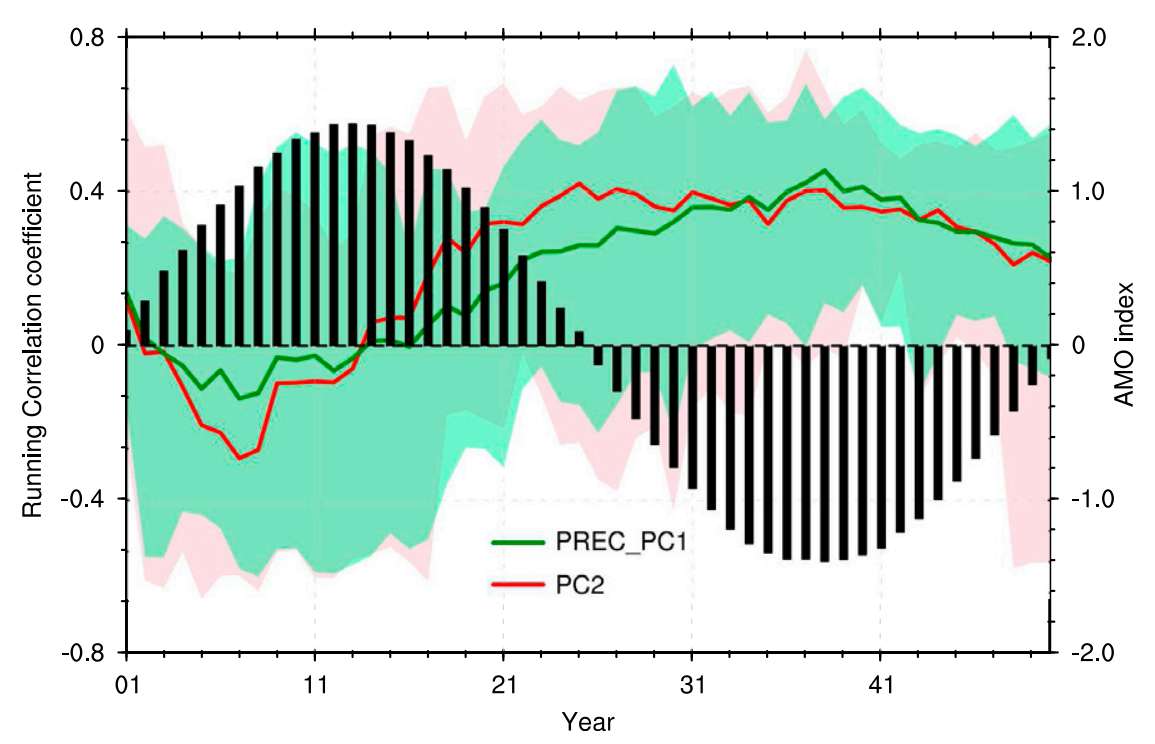

FIG. 10. The composite AMO index (black bar) and the 15-yr running correlation for the DJF Niño-3.4 index with 1) the subsequent MAM PC2 (red solid curve) and 2) the PREC_PC1 (the leading PC of MAM precipitation anomalies in East China $\left(15^{\circ}-55^{\circ} \mathrm{N}\right.$, $100^{\circ}-135^{\circ} \mathrm{E}$ ); green solid curve) for the AMO cycle based on the AMO-forced CGCM simulations. Because of the phase shift, the simulation has nine 50-yr AMO cycles, and the ensemble spreads among the running correlations are displayed by pink and green shadings for the positive and negative AMO phases, respectively.

relationship, the MAM PREC_PC1 response to ENSO also displays biased but qualitatively similar pronounced decadal variations as seen in observations, with a negative AMO corresponding to an enhanced ENSO/PREC_PC1 relationship. These results can still be obtained by considering the spread among each 50-yr AMO cycle in the simulation.
To uncover the possible reasons for this AMO modulation, the composite equatorial $\left(4^{\circ} \mathrm{S}-4^{\circ} \mathrm{N}\right)$ thermocline depth and surface zonal wind difference for the positive and negative AMO phases are displayed in Fig. 11 based on the model simulation. Here, the depth of the thermocline is defined as the ocean layer for which the vertical thermal gradient is maximized (Castaño-Tierno

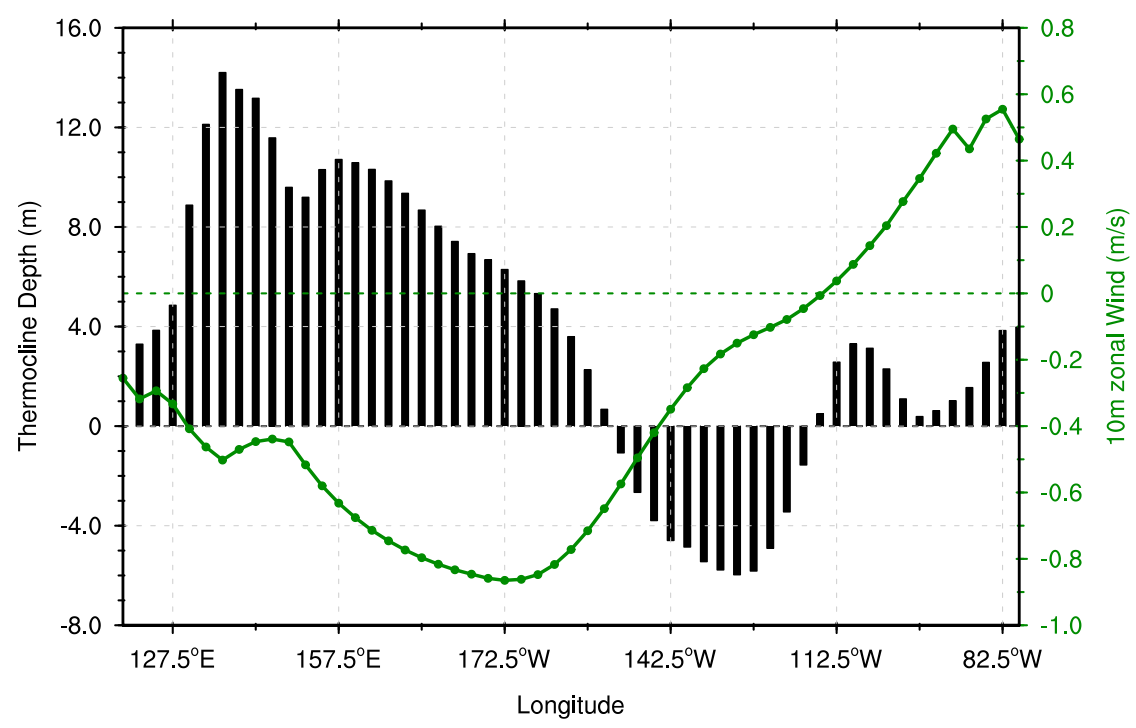

FIG. 11. Composite thermocline depth (black bars in $\mathrm{m}$ ) and the surface zonal wind (green curve in $\left.\mathrm{m} \mathrm{s}^{-1}\right)$ difference in equatorial $\left(4^{\circ} \mathrm{S}-4^{\circ} \mathrm{N}\right)$ Pacific between the positive and negative AMO phases based on the AMO-forced CGCM simulations. 


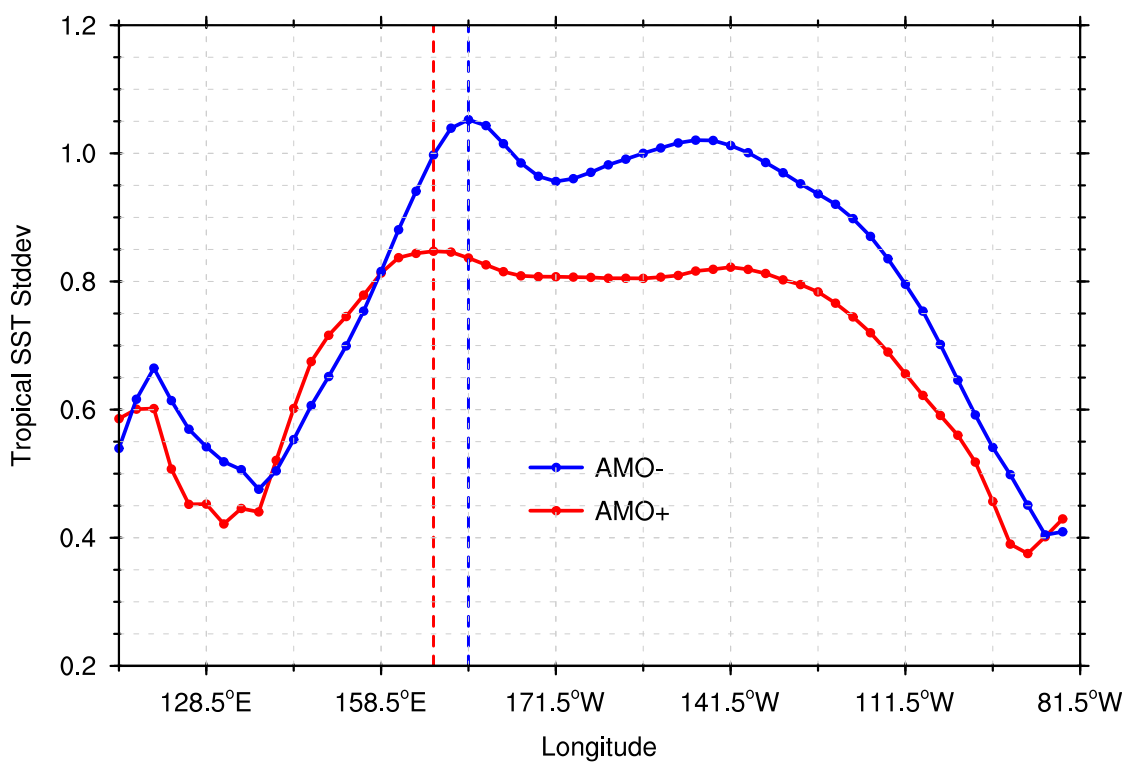

FIG. 12. The standard deviation of the DJF SST anomalies in the equatorial $\left(4^{\circ} \mathrm{S}-4^{\circ} \mathrm{N}\right)$ Pacific during the positive (red solid curve) and negative (blue solid curve) AMO phases based on the AMO-forced CGCM simulations. The vertical dashed lines denote the corresponding longitudinal positions of the maximum standard deviations for the positive and negative AMO phases.

et al. 2018). It can be seen that a positive AMO is accompanied by enhanced trade winds in the western and central tropical Pacific and an increased tilt of the equatorial Pacific thermocline, consistent with former studies (Dong et al. 2006; Li et al. 2016). This could weaken the coupled instability through which El Niño events grow (Zebiak and Cane 1987; Jin et al. 2006), hence reducing ENSO variance. Figure 12 displays model-simulated standard deviation of the equatorial $\left(4^{\circ} \mathrm{S}-4^{\circ} \mathrm{N}\right)$ SST anomalies during the boreal winter season for the positive and negative AMO phases, respectively. We can see that the relatively weaker ENSO variability during the positive AMO phase is realistically captured by the AMO-forced experiment. Furthermore, compared with the negative AMO phase, ENSO-associated SST variability tends to be shifted more westward during the positive AMO phase. However, this westward shift is mainly contributed by El Niño rather than La Niña events. Compared with a negative AMO phase, the maximum equatorial SST anomaly for El Niño distinctly shifts to the west during a positive AMO phase, which is consistent with the observations (Figs. 8a,b). On the contrary, La Niña is characterized by an eastward shifted equatorial DJF SST anomaly during a positive AMO phase. Although a slight eastward shift of the La Niña SST anomaly can also be detected in observations (Figs. 8c,d), it is exaggerated in this CGCM experiment. This may be associated with model biases in the simulation of La Niña events. Nevertheless, a relatively weaker ENSO variability and westward shifted El Niño events during a positive AMO phase are realistically reproduced by the AMO-forced experiment. These agreements between observations and CGCM simulations increase our confidence for the aforementioned mechanisms explaining the decadal modulation of the ENSO/C-mode relationship by the AMO.

\section{Conclusions and discussion}

The present study demonstrates decadal variations of the ENSO/AC interactions due to AMO forcing based on both observations and a climate model experiment. The ENSO/AC interactions, which yield combination tones in atmospheric circulations, can be typically largely represented by the second EOF of the surface wind anomalies over the tropical Pacific (i.e., C-mode). An El Niño event is generally accompanied by a strong positive phase of the $\mathrm{C}$-mode response during the boreal spring season after its peak phase. However, the ENSO/ C-mode linkage exhibits pronounced decadal variations, which are associated with changes of the AMO phase. During a negative AMO phase, we find a statistically significant positive correlation $(R=0.79,99 \%$ confidence level) between ENSO and C-mode, while this association is weakened for a positive AMO phase. The anomalous WNP anticyclone, which is a main atmospheric component of the C-mode, exhibits a similar decadal varying statistical relationship with the preceding 
winter Niño-3.4 index. Only during an AMO negative phase can we observe a pronounced anomalous WNP anticyclone in the El Niño decaying spring. As the key bridge linking ENSO and the East Asian monsoon, the anomalous WNP anticyclone enhances moisture transport to East Asia and thereby causes more precipitation in southern China. The leading PCs of the spring precipitation anomalies in southern China also exhibit a similar varying statistical relationship with the preceding winter tropical Pacific ENSO events on decadal time scales. They show a statistically significant positive correlation only during a negative AMO phase. Importantly, these atmospheric responses cannot be detected with statistical confidence during a positive AMO phase.

We suggest that these decadal variations of the ENSO/C-mode relationship are mainly attributable to ENSO magnitude and El Niño zonal structure changes due to an AMO modulation. On one hand, during the negative AMO phase, both El Niño and La Niña events tend to be stronger than those during a positive AMO phase. The possible mechanism can be summarized as an "atmospheric bridge-thermocline feedback." It includes a reduction in trade wind strength in the western and central tropical Pacific and a shallower thermocline in the equatorial Pacific due to a multidecadal cooing of the North Atlantic. These atmospheric and oceanic responses enhance the vertical stratification in the equatorial Pacific, which could lead to an intensification of the thermocline feedback and thus result in a strengthening of ENSO activity (Dong et al. 2006; Dong and Sutton 2007; Zhang and Delworth 2005; Timmermann et al. 2007; Kang et al. 2014). According to the theoretical expression of the C-mode [Eq. (1)], larger ENSO amplitude inevitably yields stronger ENSO/AC interactions and an enhanced C-mode index. On the other hand, although the longitudinal location of the La Niña SST anomaly center seems to be invariant with the AMO phase, El Niño bears distinct zonal structures of its SST anomaly during different AMO phases. El Niño events concurrent with a positive AMO phase tend to mature with a westward-shifted SST anomaly in the tropical Pacific (relative to El Niño events during a negative AMO phase). This might be associated with an intensified subtropical Pacific high and/or stronger-than-average background trade winds induced by the anomalously warm North Atlantic via the atmospheric bridge, which tends to favor a westward shift of ENSO SST anomalies (Yu et al. 2015; Hu and Fedorov 2018). These westward-shifted SST anomalies in turn tend to excite relatively symmetric convection anomalies on both sides of the equator in the central Pacific (Zhang et al. 2015). As a consequence, the meridional asymmetric $\mathrm{C}$-mode wind response is significantly reduced. The AMO-forced pacemaker CGCM experiment is capable of realistically reproducing this AMOdependent decadal varying $\mathrm{C}$-mode response during the ENSO decaying boreal spring season, which strengthens our confidence in the hypothesis of a decadal ENSO/Cmode relationship modulation by the AMO. However, given that different climate models exhibit different ENSO characteristics (and potentially different responses to an AMO forcing), we emphasize that it would be valuable to conduct similar experiments with other models in the future to test the robustness of the proposed mechanism.

Our study indicates that it is not sufficient to only focus on near-annual to interannual time scales when assessing ENSO and its interactions with the AC. We showed that decadal variability associated with the AMO can have important implications for both seasonally modulated intrinsic ENSO dynamics and their climate impacts. In fact, this AMO modulation on ENSO properties suggests a pronounced influence from the Atlantic onto the Pacific via pantropical climate interactions, which are highlighted by many recent studies (e.g., Kug and Kang 2006; Ham et al. 2013; Wang et al. 2017; Cai et al. 2019). In addition, ENSO property and C-mode changes could also be associated with other forcings, such as the Pacific decadal oscillation (PDO) (e.g., Yeh and Kirtman 2005; Verdon and Franks 2006; Kravtsov 2012; Chung and Li 2013; Lin et al. 2018) or changes in greenhouse gases and/or aerosols (e.g., Emile-Geay et al. 2008; Yeh et al. 2009; Cai et al. 2014, 2015). Research on C-mode dynamics and impacts are still at an early stage, with nonlinear processes in the ocean-atmosphere coupled system, their multiscale interactions, and their climate impacts being important targets for further investigations.

Acknowledgments. We thank the Editor in Chief and three anonymous reviewers, for their feedback that significantly improved the paper. This work was jointly supported by the National Key Research and Development Program on Monitoring, Early Warning and Prevention of Major Natural Disaster (2018YFC1506002), the National Natural Science Foundation of China (41905073), the General Program of Natural Science Foundation of Jiangsu Higher Education Institutions (19KJB170007), and the Startup Foundation for Introducing Talent of NUIST (2018r066). This paper is funded by SOEST contribution 10917 and IPRC contribution 1432.

\section{REFERENCES}

Ashok, K., S. K. Behera, S. A. Rao, H. Weng, and T. Yamagata, 2007: El Niño Modoki and its possible teleconnection. J. Geophys. Res., 112, C11007, https://doi.org/10.1029/2006JC003798. 
Battisti, D. S., and A. C. Hirst, 1989: Interannual variability in a tropical atmosphere-ocean model: Influence of the basic state, ocean geometry and nonlinearity. J. Atmos. Sci., 46, 1687-1712, https://doi.org/10.1175/1520-0469(1989)046<1687:IVIATA> 2.0.CO;2.

Bellenger, H., E. Guilyardi, J. Leloup, M. Lengaigne, and J. Vialard, 2014: ENSO representation in climate models: From CMIP3 to CMIP5. Climate Dyn., 42, 1999-2018, https:// doi.org/10.1007/s00382-013-1783-z.

Bjerknes, J., 1969: Atmospheric teleconnections from the equatorial Pacific. Mon. Wea. Rev., 97, 163-172, https://doi.org/ 10.1175/1520-0493(1969)097<0163:ATFTEP>2.3.CO;2.

Cai, W., and Coauthors, 2014: Increasing frequency of extreme El Niño events due to greenhouse warming. Nat. Climate Change, 4, 111-116, https://doi.org/10.1038/nclimate2100.

- - , and Coauthors, 2015: ENSO and greenhouse warming. Nat. Climate Change, 5, 849-859, https://doi.org/10.1038/ nclimate 2743

- and Coauthors, 2019: Pantropical climate interactions. Science, 363, eaav4236, https://doi.org/10.1126/science.aav4236.

Castaño-Tierno, A., E. Mohino, B. Rodríguez-Fonseca, and T. Losada, 2018: Revisiting the CMIP5 thermocline in the equatorial Pacific and Atlantic Oceans. Geophys. Res. Lett., 45, 12 963-12 971, https://doi.org/10.1029/2018GL079847.

Chen, M., P. Xie, J. E. Janowiak, and P. A. Arkin, 2002: Global land precipitation: A 50-yr monthly analysis based on gauge observations. J. Hydrometeor., 3, 249-266, https://doi.org/ 10.1175/1525-7541(2002)003<0249:GLPAYM > 2.0.CO;2.

Chung, P.-H., and T. Li, 2013: Interdecadal relationship between the mean state and El Niño types. J. Climate, 26, 361-379, https://doi.org/10.1175/JCLI-D-12-00106.1.

Dong, B., and R. T. Sutton, 2007: Enhancement of ENSO variability by a weakened Atlantic thermohaline circulation in a coupled GCM. J. Climate, 20, 4920-4939, https://doi.org/ 10.1175/JCLI4284.1.

,$- \ldots$, and A. A. Scaife, 2006: Multidecadal modulation of El Niño-Southern Oscillation (ENSO) variance by Atlantic Ocean sea surface temperatures. Geophys. Res. Lett., 33, L08705, https://doi.org/10.1029/2006GL025766.

Emile-Geay, J., R. Seager, M. A. Cane, E. R. Cook, and G. H. Haug, 2008: Volcanoes and ENSO over the past millennium. J. Climate, 21,3134-3148, https://doi.org/10.1175/2007JCLI1884.1.

Galbraith, E. D., and Coauthors, 2011: Climate variability and radiocarbon in the $\mathrm{CM} 2 \mathrm{Mc}$ Earth system model. J. Climate, 24, 4230-4254, https://doi.org/10.1175/2011JCLI3919.1.

Geng, X., W. Zhang, M. F. Stuecker, P. Liu, F.-F. Jin, and G. Tan, 2017: Decadal modulation of the ENSO-East Asian winter monsoon relationship by the Atlantic multidecadal oscillation. Climate Dyn., 49, 2531-2544, https://doi.org/10.1007/s00382016-3465-0.

-, , F.-F. Jin, and M. F. Stuecker, 2018: A new method for interpreting nonstationary running correlations and its application to the ENSO-EAWM relationship. Geophys. Res. Lett., 45, 327-334, https://doi.org/10.1002/2017GL076564.

Guilyardi, E., A. Wittenberg, A. Fedorov, M. Collins, C. Wang, A. Capotondi, G. J. van Oldenborgh, and T. Stockdale, 2009: Understanding El Niño in ocean-atmosphere general circulation models: Progress and challenges. Bull. Amer. Meteor Soc., 90, 325-340, https://doi.org/10.1175/2008BAMS2387.1.

Ham, Y.-G., J.-S. Kug, J.-Y. Park, and F.-F. Jin, 2013: Sea surface temperature in the north tropical Atlantic as a trigger for El Niño/Southern Oscillation events. Nat. Geosci., 6, 112-116, https://doi.org/10.1038/ngeo1686.
Harrison, D. E., 1987: Monthly mean island surface winds in the central tropical Pacific and El Niño events. Mon. Wea. Rev., 115, 3133-3145, https://doi.org/10.1175/1520-0493(1987)115<3133: MMISWI > 2.0.CO;2.

— Geophys. Res. Lett., 26, 1593-1596, https://doi.org/10.1029/ 1999 GL900316.

Hu, S., and A. V. Fedorov, 2018: Cross-equatorial winds control El Niño diversity and change. Nat. Climate Change, 8, 798-802, https://doi.org/10.1038/s41558-018-0248-0.

Jin, F.-F., 1997a: An equatorial ocean recharge paradigm for ENSO. Part I: Conceptual model. J. Atmos. Sci., 54, 811-829, https://doi.org/10.1175/1520-0469(1997)054<0811:AEORPF> 2.0.CO;2.

1997b: An equatorial ocean recharge paradigm for ENSO. Part II: A stripped-down coupled model. J. Atmos. Sci., 54, 830-847, https://doi.org/10.1175/1520-0469(1997)054<0830: AEORPF $>2.0 . \mathrm{CO} ; 2$.

— J. D. Neelin, and M. Ghil, 1994: El Niño on the Devil's staircase: Annual subharmonic steps to chaos. Science, 264, 70-72, https://doi.org/10.1126/science.264.5155.70.

_ - S. T. Kim, and L. Bejarano, 2006: A coupled-stability index for ENSO. Geophys. Res. Lett., 33, L23708, https://doi.org/ 10.1029/2006GL027221.

Kalnay, E., and Coauthors, 1996: The NCEP/NCAR 40-Year Reanalysis Project. Bull. Amer. Meteor. Soc., 77, 437-471, https:// doi.org/10.1175/1520-0477(1996)077<0437:TNYRP>2.0.CO;2.

Kang, I.-S., H. No, and F. Kucharski, 2014: ENSO amplitude modulation associated with the mean SST changes in the tropical central Pacific induced by Atlantic multidecadal oscillation. J. Climate, 27, 7911-7920, https://doi.org/10.1175/ JCLI-D-14-00018.1.

Kravtsov, S., 2012: An empirical model of decadal ENSO variability. Climate Dyn., 39, 2377-2391, https://doi.org/10.1007/ s00382-012-1424-y.

Kucharski, F., I.-S. Kang, R. Farneti, and L. Feudale, 2011: Tropical Pacific response to 20th century Atlantic warming. Geophys. Res. Lett., 38, L03702, https://doi.org/10.1029/ 2010 GL046248.

Kug, J.-S., and I.-S. Kang, 2006: Interactive feedback between ENSO and the Indian Ocean. J. Climate, 19, 1784-1801, https://doi.org/10.1175/JCLI3660.1.

Levine, A. F. Z., M. J. McPhaden, and D. M. W. Frierson, 2017: The impact of the AMO on multidecadal ENSO variability. Geophys. Res. Lett., 44, 3877-3886, https://doi.org/10.1002/ 2017GL072524.

— D. M. W. Frierson, and M. J. McPhaden, 2018: AMO forcing of multidecadal Pacific ITCZ variability. J. Climate, 31, 57495764, https://doi.org/10.1175/JCLI-D-17-0810.1.

Li, X., S.-P. Xie, S. T. Gille, and C. Yoo, 2016: Atlantic-induced pan-tropical climate change over the past three decades. Nat. Climate Change, 6, 275-279, https://doi.org/10.1038/ nclimate2840.

Lin, R., F. Zheng, and X. Dong, 2018: ENSO frequency asymmetry and the Pacific decadal oscillation in observations and 19 CMIP5 models. Adv. Atmos. Sci., 35, 495-506, https://doi.org/ 10.1007/s00376-017-7133-z.

Lübbecke, J. F., and M. J. McPhaden, 2014: Assessing the twentyfirst-century shift in ENSO variability in terms of the Bjerknes stability index. J. Climate, 27, 2577-2587, https://doi.org/ 10.1175/JCLI-D-13-00438.1.

McGregor, S., A. Timmermann, N. Schneider, M. F. Stuecker, and M. H. England, 2012: The effect of the South Pacific con- 
vergence zone on the termination of El Niño events and the meridional asymmetry of ENSO. J. Climate, 25, 5566-5586, https://doi.org/10.1175/JCLI-D-11-00332.1.

—, N. Ramesh, P. Spence, M. H. England, M. J. McPhaden, and A. Santoso, 2013: Meridional movement of wind anomalies during ENSO events and their role in event termination. Geophys. Res. Lett., 40, 749-754, https://doi.org/10.1002/grl.50136.

_ , A. Timmermann, M. F. Stuecker, M. H. England, M. Merrifield, F. Jin, and Y. Chikamoto, 2014: Recent Walker circulation strengthening and Pacific cooling amplified by Atlantic warming. Nat. Climate Change, 4, 888-892, https://doi.org/ 10.1038/nclimate2330.

McPhaden, M. J., S. E. Zebiak, and M. H. Glantz, 2006: ENSO as an integrating concept in Earth science. Science, 314, 17401745, https://doi.org/10.1126/science.1132588.

Meinen, C. S., and M. J. McPhaden, 2000: Observations of warm water volume changes in the equatorial Pacific and their relationship to El Niño and La Niña. J. Climate, 13, 3551-3559, https://doi.org/10.1175/1520-0442(2000)013<3551:OOWWVC> 2.0.CO;2.

Neelin, J. D., D. S. Battisti, A. C. Hirst, F.-F. Jin, Y. Wakata, T. Yamagata, and S. E. Zebiak, 1998: ENSO theory. J. Geophys. Res., 103, 14261-14 290, https://doi.org/10.1029/97JC03424.

North, G. R., T. L. Bell, R. F. Cahalan, and F. J. Moeng, 1982: Sampling errors in the estimation of empirical orthogonal functions. Mon. Wea. Rev., 110, 699-706, https://doi.org/10.1175/ 1520-0493(1982)110<0699:SEITEO > 2.0.CO;2.

Ohba, M., and H. Ueda, 2009: Role of nonlinear atmospheric response to SST on the asymmetric transition process of ENSO. J. Climate, 22, 177-192, https://doi.org/10.1175/2008JCLI2334.1.

Park, J.-H., and T. Li, 2019: Interdecadal modulation of El Niñotropical North Atlantic teleconnection by the Atlantic multidecadal oscillation. Climate Dyn., 52, 5345-5360, https:// doi.org/10.1007/s00382-018-4452-4.

Picaut, J., F. Masia, and Y. du Penhoat, 1997: An advectivereflective conceptual model for the oscillatory nature of the ENSO. Science, 277, 663-666, https://doi.org/10.1126/ science. 277.5326 .663 .

Rasmusson, E. M., and T. H. Carpenter, 1982: Variations in tropical sea surface temperature and surface wind fields associated with the Southern Oscillation/El Niño. Mon. Wea. Rev., 110, 354-384, https://doi.org/10.1175/1520-0493(1982)110<0354: VITSST $>2.0 . \mathrm{CO} ; 2$.

Ren, H.-L., F.-F. Jin, M. F. Stuecker, and R. Xie, 2013: ENSO regime change since the late 1970s as manifested by two types of ENSO. Kisho Shushi. Dai2shu, 91, 835-842, https://doi.org/ 10.2151/jmsj.2013-608.

_ J. Zuo, F.-F. Jin, and M. F. Stuecker, 2016: ENSO and annual cycle interaction: The combination mode representation in CMIP5 models. Climate Dyn., 46, 3753-3765, https://doi.org/ 10.1007/s00382-015-2802-z.

Ropelewski, C. F., and M. S. Halpert, 1987: Global and regional scale precipitation patterns associated with the El Niño/Southern Oscillation. Mon. Wea. Rev., 115, 1606-1626, https://doi.org/ 10.1175/1520-0493(1987)115<1606:GARSPP > 2.0.CO;2.

Schopf, P. S., and M. J. Suarez, 1988: Vacillations in a coupled ocean-atmosphere model. J. Atmos. Sci., 45, 549-566, https://doi.org/10.1175/1520-0469(1988)045<0549:VIACOM> 2.0.CO;2.

Smith, T. M., R. W. Reynolds, T. C. Peterson, and J. Lawrimore, 2008: Improvements to NOAA's historical merged landocean surface temperature analysis (1880-2006). J. Climate, 21, 2283-2296, https://doi.org/10.1175/2007JCLI2100.1.
Stein, K., A. Timmermann, and N. Schneider, 2011: Phase synchronization of the El Niño-Southern Oscillation with the annual cycle. Phys. Rev. Lett., 107, 128501, https://doi.org/ 10.1103/PhysRevLett.107.128501.

,,,--- F.-F. Jin, and M. F. Stuecker, 2014: ENSO seasonal synchronization theory. J. Climate, 27, 5285-5310, https://doi.org/10.1175/JCLI-D-13-00525.1.

Stuecker, M. F., A. Timmermann, F.-F. Jin, S. McGregor, and H.-L. Ren, 2013: A combination mode of the annual cycle and the El Nino/Southern Oscillation. Nat. Geosci., 6, 540-544, https://doi.org/10.1038/ngeo1826.

_ , F.-F. Jin, and A. Timmermann, 2015a: El Niño-Southern Oscillation frequency cascade. Proc. Natl. Acad. Sci. USA, 112, 13 490-13 495, https://doi.org/10.1073/pnas.1508622112.

,,--- , and S. McGregor, 2015b: Combination mode dynamics of the anomalous northwest Pacific anticyclone. J. Climate, 28, 1093-1111, https://doi.org/10.1175/JCLI-D14-00225.1.

Timmermann, A., and Coauthors, 2007: The influence of a weakening of the Atlantic meridional overturning circulation on ENSO. J. Climate, 20, 4899-4919, https://doi.org/10.1175/ JCLI4283.1.

Trenberth, K. E., and J. M. Caron, 2000: The Southern Oscillation revisited: Sea level pressures, surface temperatures, and precipitation. J. Climate, 13, 4358-4365, https://doi.org/10.1175/ 1520-0442(2000)013<4358:TSORSL > 2.0.CO;2.

—, and D. J. Shea, 2006: Atlantic hurricanes and natural variability in 2005. Geophys. Res. Lett., 33, L12704, https://doi.org/ 10.1029/2006GL026894.

van Loon, H., and R. A. Madden, 1981: The Southern Oscillation. Part I: Global associations with pressure and temperature in northern winter. Mon. Wea. Rev., 109, 1150-1162, https://doi.org/10.1175/1520-0493(1981)109<1150:TSOPIG > 2.0.CO;2.

Van Oldenborgh, G. J., S. Y. Philip, and M. Collins, 2005: El Niño in a changing climate: A multi-model study. Ocean Sci., 1, 8195, https://doi.org/10.5194/os-1-81-2005.

Vecchi, G. A., 2006: The termination of the 1997-98 El Niño. Part II: Mechanisms of atmospheric change. J. Climate, 19, 26472664, https://doi.org/10.1175/JCLI3780.1.

Verdon, D. C., and S. W. Franks, 2006: Long-term behaviour of ENSO: Interactions with the PDO over the past 400 years inferred from paleoclimate records. Geophys. Res. Lett., 33, L06712, https://doi.org/10.1029/2005GL025052.

Wallace, J. M., E. M. Rasmusson, T. P. Mitchell, V. E. Kousky, E. S. Sarachik, and H. von Storch, 1998: On the structure and evolution of ENSO-related climate variability in the tropical Pacific: Lessons from TOGA. J. Geophys. Res., 103, $14241-$ 14 259, https://doi.org/10.1029/97JC02905.

Wang, B., R. Wu, and X. Fu, 2000: Pacific-East Asian teleconnection: How does ENSO affect East Asian climate? J. Climate, 13, 1517-1536, https://doi.org/10.1175/1520-0442(2000)013<1517: PEATHD $>2.0 . \mathrm{CO} ; 2$.

_ J. Yang, T. Zhou, and B. Wang, 2008: Interdecadal changes in the major modes of Asian-Australian monsoon variability: Strengthening relationship with ENSO since the late 1970s. J. Climate, 21, 1771-1789, https://doi.org/10.1175/2007JCLI1981.1.

Wang, L., J.-Y. Yu, and H. Paek, 2017: Enhanced biennial variability in the Pacific due to Atlantic capacitor effect. Nat. Commun., 8, 14887, https://doi.org/10.1038/ncomms14887.

Weisberg, R. H., and C. Wang, 1997: A western Pacific oscillator paradigm for the El Niño-Southern Oscillation. Geophys. Res. Lett., 24, 779-782, https://doi.org/10.1029/97GL00689. 
Widlansky, M. J., A. Timmermann, S. McGregor, M. F. Stuecker, and W. Cai, 2014: An interhemispheric tropical sea level seesaw due to El Niño Taimasa. J. Climate, 27, 1070-1081, https://doi.org/10.1175/JCLI-D-13-00276.1.

Wyrtki, K., 1975: El Niño-The dynamic response of the equatorial Pacific oceanto atmospheric forcing. J. Phys. Oceanogr., 5, 572-584, https://doi.org/10.1175/1520-0485(1975)005<0572: ENTDRO $>2.0 . \mathrm{CO} ; 2$.

Xiang, B., B. Wang, and T. Li, 2013: A new paradigm for the predominance of standing central Pacific warming after the late 1990s. Climate Dyn., 41, 327-340, https://doi.org/10.1007/ s00382-012-1427-8.

Xie, S.-P., K. Hu, J. Hafner, H. Tokinaga, Y. Du, G. Huang, and T. Sampe, 2009: Indian Ocean capacitor effect on Indo-western Pacific climate during the summer following El Niño. J. Climate, 22, 730-747, https://doi.org/10.1175/2008JCLI2544.1.

- , Y. Du, G. Huang, X.-T. Zheng, H. Tokinaga, K. Hu, and Q. Liu, 2010: Decadal shift in El Niño influences on Indowestern Pacific and East Asian climate in the 1970s. J. Climate, 23, 3352-3368, https://doi.org/10.1175/2010JCLI3429.1.

Yamagata, T., S. K. Behera, J.-J. Luo, S. Masson, M. R. Jury, and S. A. Rao, 2004: Coupled ocean-atmosphere variability in the tropical Indian Ocean. Earth Climate: The Ocean-Atmosphere Interaction, Geophys. Monogr., Vol. 147, Amer. Geophys. Union, 189-211.

Yang, J., Q. Liu, S.-P. Xie, Z. Liu, and L. Wu, 2007: Impact of the Indian Ocean SST basin mode on the Asian summer monsoon. Geophys. Res. Lett., 34, L02708, https://doi.org/10.1029/ 2006GL028571.

- - Z Z. Liu, L. Wu, and F. Huang, 2009: Basin mode of Indian Ocean sea surface temperature and Northern Hemisphere circumglobal teleconnection. Geophys. Res. Lett., 36, L19705, https://doi.org/10.1029/2009GL039559.

Yeh, S.-W., and B. P. Kirtman, 2005: Pacific decadal variability and decadal ENSO amplitude modulation. Geophys. Res. Lett., 32, L05703, https://doi.org/10.1029/2004GL021731.

_ J.-S. Kug, B. Dewitte, M.-H. Kwon, B. P. Kirtman, and F.-F. Jin, 2009: El Niño in a changing climate. Nature, 461, 511-514, https://doi.org/10.1038/nature08316.

You, Y., and X. Jia, 2018: Interannual variations and prediction of spring precipitation over China. J. Climate, 31, 655-670, https://doi.org/10.1175/JCLI-D-17-0233.1.
Yu, J.-Y., P. Kao, H. Paek, H.-H. Hsu, C. Hung, M.-M. Lu, and S.-I. An, 2015: Linking emergence of the central Pacific El Niño to the Atlantic multidecadal oscillation. J. Climate, 28, 651-662, https://doi.org/10.1175/JCLI-D-14-00347.1.

Zanchettin, D., O. Bothe, H. F. Graf, N.-E. Omrani, A. Rubino, and J. H. Jungclaus, 2016: A decadally delayed response of the tropical Pacific to Atlantic multidecadal variability. Geophys. Res. Lett., 43, 784-792, https://doi.org/10.1002/ 2015 GL067284.

Zebiak, S. E., and M. A. Cane, 1987: A model El Niño-Southern Oscillation. Mon. Wea. Rev., 115, 2262-2278, https://doi.org/ 10.1175/1520-0493(1987)115<2262:AMENO>2.0.CO;2.

Zhang, R., and T. L. Delworth, 2005: Simulated tropical response to a substantial weakening of the Atlantic thermohaline circulation. J. Climate, 18, 1853-1860, https://doi.org/10.1175/ JCLI3460.1.

_- A. Sumi, and M. Kimoto, 1996: Impact of El Niño on the East Asian monsoon: A diagnostic study of the '86/87 and '91/92 events. J. Meteor. Soc. Japan, 74, 49-62, https://doi.org/ 10.2151/jmsj1965.74.1_49.

_ Q Q. Min, and J. Su, 2017: Impact of El Niño on atmospheric circulations over East Asia and rainfall in China: Role of the anomalous western North Pacific anticyclone. Sci. China Earth Sci., 60, 1124-1132, https://doi.org/10.1007/ s11430-016-9026-x.

Zhang, W., F.-F. Jin, and A. Turner, 2014: Increasing autumn drought over southern China associated with ENSO regime shift. Geophys. Res. Lett., 41, 4020-4026, https://doi.org/ 10.1002/2014GL060130.

, H. Li, F.-F. Jin, M. F. Stuecker, A. G. Turner, and N. P. Klingaman, 2015: The annual-cycle modulation of meridional asymmetry in ENSO's atmospheric response and its dependence on ENSO zonal structure. J. Climate, 28, 5795-5812, https://doi.org/10.1175/JCLI-D-14-00724.1.

$\longrightarrow,-$, M. F. Stuecker, F.-F. Jin, and A. G. Turner, 2016a: A new understanding of El Niño's impact over East Asia: Dominance of the ENSO combination mode. J. Climate, 29, 4347-4359, https://doi.org/10.1175/JCLI-D-15-0104.1.

, and Coauthors, 2016b: Unraveling El Niño's impact on the East Asian monsoon and Yangtze River summer flooding. Geophys. Res. Lett., 43, 11375-11382, https://doi.org/10.1002/ 2016GL071190. 